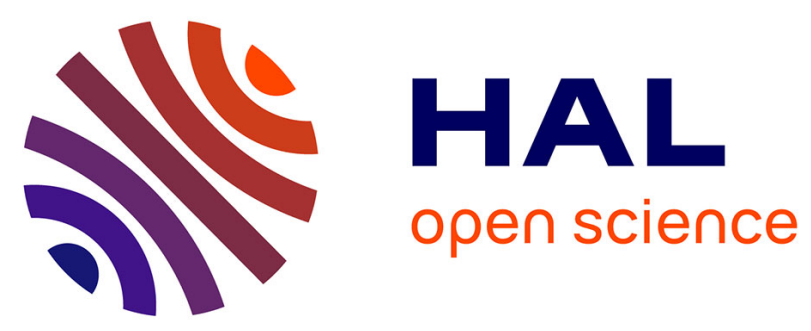

\title{
Lightning-induced lower-hybrid turbulence and trapped Extremely Low Frequency (ELF) electromagnetic waves observed in deep equatorial plasma density depletions during intense magnetic storms
}

Michel Malingre, Jean-Jacques Berthelier, R. Pfaff, J. Jasperse, Michel Parrot

\section{- To cite this version:}

Michel Malingre, Jean-Jacques Berthelier, R. Pfaff, J. Jasperse, Michel Parrot. Lightning-induced lower-hybrid turbulence and trapped Extremely Low Frequency (ELF) electromagnetic waves observed in deep equatorial plasma density depletions during intense magnetic storms. Journal of Geophysical Research Space Physics, 2008, 113 (A11), pp.A11320. 10.1029/2008JA013463 . hal-00158107

\author{
HAL Id: hal-00158107 \\ https://hal.science/hal-00158107
}

Submitted on 11 Feb 2016

HAL is a multi-disciplinary open access archive for the deposit and dissemination of scientific research documents, whether they are published or not. The documents may come from teaching and research institutions in France or abroad, or from public or private research centers.
L'archive ouverte pluridisciplinaire HAL, est destinée au dépôt et à la diffusion de documents scientifiques de niveau recherche, publiés ou non, émanant des établissements d'enseignement et de recherche français ou étrangers, des laboratoires publics ou privés. 


\title{
Lightning-induced lower-hybrid turbulence and trapped Extremely Low Frequency (ELF) electromagnetic waves observed in deep equatorial plasma density depletions during intense magnetic storms
}

\author{
M. Malingre, ${ }^{1}$ J.-J. Berthelier, ${ }^{1}$ R. Pfaff, ${ }^{2}{ }$. Jasperse, ${ }^{3}$ and M. Parrot ${ }^{4}$ \\ Received 6 June 2008; revised 27 August 2008; accepted 25 September 2008; published 26 November 2008.
}

[1] During the early phase of the intense magnetic storm of 7-11 November 2004, the DEMETER satellite encountered large-scale equatorial plasma density depletions with density decreases of two or three orders of magnitude. Wave measurements carried out inside these depletions show the occurrence of broadband and localized lower-hybrid turbulence triggered by whistlers propagating from thunderstorm lightning occurring below the orbit path. High-sample-rate waveforms reveal that this lower-hybrid turbulence can evolve into localized large-amplitude quasi-monochromatic wave packets similar to lower-hybrid structures that were, up to now, only observed in the auroral regions, usually on high-latitude magnetic field lines associated with discrete aurora. These equatorial structures have typical amplitudes of up to $20 \mathrm{mV} / \mathrm{m}$ and durations of $\sim 20-30 \mathrm{~ms}$. Simultaneous thermal ion measurements show that these bursts are often correlated with small-scale density depletions of 5-10\%. Although the lower-hybrid structures are less intense than those observed in the auroral zone and although their energy source is different, our observations lend support to the idea that the formation of lower-hybrid structures is an universal mechanism operating in inhomogeneous magnetized space plasmas in the presence of VLF whistler mode turbulence. Besides the lower-hybrid turbulence, another interesting feature is the occurrence of strong narrowband electromagnetic ELF emissions with amplitudes of a few millivolts per meter at frequencies below the proton gyrofrequency. They are continuously observed throughout the entire depletion. These emissions occur not only within the depletions but also, although less intense, outside of them over a large latitudinal range. They are tentatively identified as magnetospheric line radiations (MLRs) commonly observed during magnetically disturbed periods. Similar events were observed on 15 May 2005 and on 24 August 2005 during two other intense magnetic storms.

Citation: Malingre, M., J.-J. Berthelier, R. Pfaff, J. Jasperse, and M. Parrot (2008), Lightning-induced lower-hybrid turbulence and trapped Extremely Low Frequency (ELF) electromagnetic waves observed in deep equatorial plasma density depletions during intense magnetic storms, J. Geophys. Res., 113, A11320, doi:10.1029/2008JA013463.

\section{Introduction}

[2] One of the most spectacular phenomena occurring in the low-latitude, post-sunset ionosphere during strong magnetic storms is the formation of very deep, large-scale plasma density depletions. These depletions are the signatures of either plasma bubbles or a severe uplift of the F-region plasma caused by storm-time, eastward equatorial electric fields.

\footnotetext{
${ }^{1}$ Centre d'étude des Environnements Terrestre et Planétaires/Centre National de la Recherche Scientifique, Saint-Maur-des-Fosses, France.

${ }^{2}$ Goddard Space Flight Center/National Aeronautics and Space Administration, Greenbelt, Maryland, USA.

${ }^{3}$ Air Force Research Laboratory, Hanscom Air Force Base, Bedford, Massachusetts, USA.

${ }^{4}$ Laboratoire de Physique et Chimie de l'Environnement, Orléans, France.

Copyright 2008 by the American Geophysical Union. 0148-0227/08/2008JA013463
}

[3] Equatorial plasma bubbles (EPBs) have been extensively studied both experimentally and theoretically over the last four decades [Kelley, 1989; Singh et al., 1997]. Observed mostly in the 20.00 to 23.00 LT sector, these plasma density depletions rise through the postsunset equatorial ionosphere to altitudes as high as $1000 \mathrm{~km}$. They originate in the bottomside F-region, and are driven by the generalized, Rayleigh-Taylor instability under the combined influence of gravity, eastward electric fields and vertical thermospheric neutral winds [Ott, 1978; Kelley, 1989]. The eastward polarization electric field induced inside a bubble causes it to drift upward with velocities ranging typically from a few tens of $\mathrm{ms}^{-1}$ to $\sim 500 \mathrm{~ms}^{-1}$. In some cases, vertical drift velocities as large as $2-3 \mathrm{~km} \mathrm{~s}^{-1}$ have been reported [Aggson et al., 1992; Laakso et al., 1997]. As a bubble evolves, the entire extent of its flux tube becomes depleted, which leads to a "wedge-shaped and magneticfield aligned structure" with typical dimensions of about $100 \mathrm{~km}$ in the east-west direction and as much as $2000 \mathrm{~km}$ 
in the north-south direction. The plasma density inside bubbles may be up to two or three orders of magnitude lower than the density in the undisturbed background ionosphere. EPBs occur both during magnetically quiet and active times.

[4] The equatorial, postsunset, eastward electric field drives the ionospheric plasma upward and therefore controls, to a large extent, the bottomside of the F-layer. It also controls the growth rate of the generalized Rayleigh-Taylor instability and thus plays a dominant role in the structure and dynamics of the low-latitude ionospheric plasma and in the variability of plasma bubbles. An eastward electric field favors the formation and development of plasma bubbles, whereas a westward electric field tends to inhibit the bubble activity. Storm-time equatorial electric field disturbances result from two different mechanisms: the solar windmagnetosphere dynamo and the ionospheric disturbance dynamo. Disturbances associated with the former are short-lived, with a typical timescale of about an hour, and arise from the prompt penetration of magnetospheric electric fields to low ionospheric latitudes in the early phase of the storm. Electric field perturbations associated with the latter originate from the dynamo action of storm-time neutral winds driven by Joule heating of the auroral ionosphere/thermosphere [Scherliess and Fejer, 1997]. They have a longer lifetime, with a typical timescale of a few hours, and develop from a few hours up to about one day after the onset of the magnetically disturbed period. Studies based on DMSP F9 and F10 satellite measurements have shown that the bubble activity in the evening sector is high during the initial and main phases of geomagnetic storms and is suppressed during the recovery phase [Huang et al., 2001]. This storm-phase dependence of the EPB occurrence in the evening sector has been interpreted as caused by the prompt penetration of a magnetospheric electric field to the equatorial ionosphere with an eastward component that enhances the effect of the normal dynamo electric field, and, in the recovery phase, by the stabilizing effect of longlasting ionospheric disturbance dynamo electric fields with a westward component.

[5] Promptly penetrating eastward electric fields during strong magnetic storms may be sometimes large enough to rapidly lift the low-latitude bottomside F-layer to altitudes as high as $1000 \mathrm{~km}$ or more. Large equatorial plasma density depletions extending over a wide range in latitude and/or longitude are observed along the circular orbits of the DMSP, ROCSAT-1 and KOMPSAT-1 satellites during intense magnetic storms [Greenspan et al., 1991; Basu et al., 2001; Lee et al., 2002; Su et al., 2002; Kil et al., 2006] and are often interpreted in terms of an uplift of the bottomside F-region above the satellite altitudes. This phenomenon must be distinguished from the smaller-scale structures - the so-called plasma bubbles - driven by a plasma instability. However, it is interesting to note that large plasma depletions are often observed in regions where plasma bubbles are present and have characteristics which suggest they might be the result of the merging of multiple bubbles [Kil and Paxton, 2006]. In the following sections, we use the term depletion to designate either the plasma density dropout structure associated with EPBs or the large-scale plasma density depletion associated with the uplifted ionospheric plasma.
[6] The three-axis stabilized DEMETER satellite was launched on 29 June 2004, into a polar (inclination of $98^{\circ}$ ) nearly circular (altitude $\sim 720 \mathrm{~km}$ ) quasi-heliosynchronous orbit. The orbit plane is close to the 10:30-22:30 LT meridian at low and mid latitudes and thus well suited to observe plasma density depletions in the evening sector of the equatorial ionosphere. During the intense magnetic storm of 7-11 November 2004, the DEMETER satellite crossed several deep, large-scale plasma depletions. Intense enhancements of turbulence at and just above the lowerhybrid frequency, triggered by lightning-generated whistlers were consistently observed in these depletions. Embedded in this background of turbulence, large-amplitude quasimonochromatic wave packets at the lower-hybrid frequency and of very short duration $(\sim 20 \mathrm{~ms})$ were detected. Simultaneous thermal-ion measurements from the retarding potential analyzer showed that these wave packets are often correlated with density depletions of a few $\%$ to $\sim 10 \%$. These small-scale phenomena observed in the large-scale equatorial plasma depletions bear some similarities with lower-hybrid structures (LHS) commonly observed on high-latitude magnetic field lines associated with discrete aurora. Lower-hybrid structures in the auroral zone are detected in regions with a background hiss in the lowerhybrid frequency range. They are spatially localized enhancements of the lower-hybrid wave electric field power, typically $10-15 \mathrm{~dB}$ above the background hiss level, and usually associated with density depletions typically of a few $\%$, and sometimes tens of $\%$. These LHSs, also called lower-hybrid spikelets or lower-hybrid cavitons (more appropriate when referring to density depletions associated with lower-hybrid bursts) and most often lower-hybrid solitary structures (LHSS), have been observed in the upper auroral ionosphere at altitudes from $500 \mathrm{~km}$ to $1800 \mathrm{~km}$ by several sounding rockets [LaBelle et al., 1986; Kintner et al., 1992; Vago et al., 1992; Lynch et al., 1996; Bonnell et al., 1998; Schuck et al., 1998] and by the Freja satellite [Eriksson et al., 1994; Pécseli et al., 1996; Dovner et al., 1997]. Observations of LHSs at higher altitudes in the magnetosphere around $12000 \mathrm{~km}$ by the Viking satellite and $23000 \mathrm{~km}$ by the Cluster satellites have been also reported [Tjulin et al., 2003]. The auroral structures appear as filamentary structures along the geomagnetic field $\left(\mathbf{B}_{\mathbf{o}}\right)$ with the scale size perpendicular to $\mathbf{B}_{\mathbf{0}}$ ranging by at least one order of magnitude from a few to many thermal ion gyroradii, and with the parallel size probably several orders of magnitude larger [Knudsen et al., 1999]. LHSs are frequently associated with bursts of ions accelerated perpendicular to $\mathbf{B}_{\mathbf{0}}$ [Arnoldy et al., 1992; Lynch et al., 1999]. A detailed review of the basic properties of the auroral LHSs and an overview of theories proposed to explain them may be found in the paper by Schuck et al. [2003a]. As already mentioned, LHSs are commonly observed in the auroral regions, but so far there have been no reports of similar observations at ionospheric altitudes and at low latitudes.

[7] Besides these lower-hybrid emissions, the other interesting and very intriguing feature is the existence inside the depletions of a nearly continuous, intense electromagnetic ELF emission at frequencies below the proton gyrofrequency. Finally, less intense, sporadic HF emissions above the electron plasma frequency are sometimes recorded. Similar events were observed during the strong magnetic storms of 
15 May 2005 and of 24 August 2005. The purpose of this paper is to present a detailed overview of the ELF and VLF wave emissions from a few representative events, with a special emphasis on lightning-induced, lower-hybrid turbulence and associated LHSs. After a brief description of the plasma and wave experiments in section 2 , the observations are presented in section 3 and discussed in section 4 . Conclusions are given in section 5.

\section{Instrumentation}

[8] The data presented here were acquired by the wave and plasma instruments of the DEMETER payload. There are 2 wave instruments, ICE [Berthelier et al., 2006a] to measure the 3 components of the electric field from DC to $3.25 \mathrm{MHz}$, and IMSC [Parrot et al., 2006] to measure the 3 components of the AC magnetic fields from $10 \mathrm{~Hz}$ up to $20 \mathrm{kHz}$. The satellite is operated in two modes: a burst mode where the waveforms of the six components of the $\mathrm{AC}$ electromagnetic field up to $1.2 \mathrm{kHz}$ are available together with waveforms of one electric and one magnetic component at VLF up to $20 \mathrm{kHz}$, and a survey mode in which spectra of one electric and one magnetic components are onboard computed up to $20 \mathrm{kHz}$ with a frequency resolution of $19.25 \mathrm{~Hz}$. Waveforms of the three electric field components in the ULF range are recorded in both modes. The thermal ion and electron measurements are, respectively, performed by the IAP plasma analyzer [Berthelier et al., 2006b], and the ISL Langmuir probe [Lebreton et al., 2006]. In the burst mode, the ion density, composition and temperature are obtained every $360 \mathrm{~ms}$ and the electron parameters are obtained every second. Detailed information on these experiments can be found in the above mentioned papers.

\section{Observations}

[9] On 7 November 2004, a CME-driven interplanetary shock impinged on the magnetopause, which initiated an intense geomagnetic storm (peak Dst $\sim-373 \mathrm{nT}$ ), as shown by variations of the Dst index for the 6-11 November period displayed in Figure 1 (top panel). The arrival of a new interplanetary shock in the evening of 9 November (peak Dst $\sim-289 \mathrm{nT}$ ) induced a second magnetic storm. During the main phase of these two consecutive storms, DEMETER crossed equatorial plasma bubbles and large-scale plasma depletions at local times between 22:15 LT and 22:30 LT on several orbits. A first group of events was detected on 8 November from 01:40 UT to 08:20 UT, a second one on 10 November from 06:30 UT to 13:10 UT. The dependence of the EPB occurrence in the evening LT sector on the phases of the two storms as seen by our observations is similar to that reported by Huang et al. [2001]. All detected bubbles had density drops of one to nearly three orders of magnitude below the background density outside the bubble (bottom panels of Figure 1). The data presented in the following were mainly recorded during orbit 1903 on 10 November 2005 at local times around 22:30 LT when the satellite was travelling at a velocity of $7.6 \mathrm{~km} \mathrm{~s}^{-1}$ through the equatorial ionosphere from southern to northern latitudes above active tropospheric thunderstorms in the Pacific region. This orbit has been selected because, in the region of interest, the DEMETER payload was operated in the burst mode and waveforms are therefore available.

[10] Plotted in Figure 2 from top to bottom are the ion densities, the frequency-time spectrograms of the $E_{12}$ electric field and of the $\mathrm{B}_{2}$ magnetic field components in the $0-$ $3 \mathrm{kHz}$ frequency range. $\mathrm{E}_{12}$ is along the $\mathrm{Y}$ axis of the satellite, perpendicular to the orbit plane and close to the east-west direction and, in the region of interest, makes an angle of $105^{\circ}$ with the direction of the Earth's magnetic field. $B_{2}$ is in the horizontal plane at $45^{\circ}$ from $E_{12}$. The spacecraft crossed several narrow plasma depletions, the widest and deepest between 8:14:35 UT and 8:17:00 UT. Because of the $98^{\circ}$ inclination of the orbit, DEMETER traveled at an angle of $\sim 22^{\circ}$ toward the west with respect to $\mathbf{B}_{\mathbf{o}}$ and therefore crossed this depletion approximately along its south-north extent, hence the long time the satellite stayed within it. DEMETER entered the depletion at geographic longitude and latitude of $210^{\circ}$ and $-3^{\circ}$, respectively, through its eastern edge where the plasma density dropped from $10^{5} \mathrm{~cm}^{-3}$ to $8 \times 10^{2} \mathrm{~cm}^{-3}$ in about $10 \mathrm{~s}$; then the density decreased smoothly to $2 \times 10^{2} \mathrm{~cm}^{-3}$ in $\sim 100 \mathrm{~s}$, before remaining roughly at this level until the satellite crossed the western edge at $208^{\circ}$ longitude and $+6^{\circ}$ latitude. Here the density rose to practically the same level as before the entry of the depletion. DEMETER traveled about $1100 \mathrm{~km}$ parallel to the magnetic field lines and about $250 \mathrm{~km}$ zonally during the crossing through the depletion. A detailed analysis of the variations along the orbit of the ion parameters is given in a companion paper (J. J. Berthelier et al., Observations of deep plasma bubbles and ion heating by the Demeter satellite during the November 2004 magnetic storm, manuscript in preparation, 2008; hereinafter referred to as Berthelier et al., manuscript in preparation, 2008) and will be briefly summarized here. The major ion species is $\mathrm{O}^{+}$but there is also a significant content of $\mathrm{NO}^{+}$ions (up to $\sim 30-40 \%$ of the $\mathrm{O}^{+}$ density) in the depletion. Besides the large-scale, smooth density decrease within the depleted region, a narrow structure characterized by a density enhancement from $3 \times$ $10^{2} \mathrm{~cm}^{-3}$ to $3 \times 10^{3} \mathrm{~cm}^{-3}$ and back to the previous level is observed between 8:15:30 UT and 8:15:33 UT. During this short time interval, the plasma appeared to be on the way to recover the characteristics of the undisturbed background ionospheric plasma outside of the depletion. This feature was interpreted by Berthelier et al. [2008] as indicating that the depletion was starting to bifurcate, giving rise to two smaller depletions, D1 east of the bifurcation point and D2 west of it.

[11] As shown in Figures 2 and 3, several kinds of plasma waves are detected in the vicinity and inside the deep plasma depletion. A broadband electrostatic ELF turbulence at frequencies from 0 up to about the proton gyrofrequency $\omega_{c H} \sim 350 \mathrm{~Hz}$ (and even more at 8:17:00 UT) is observed at the edges of the depletion, coincident with strong, plasma density gradients and fluctuations in the DC perpendicular electric field. This turbulence is likely due to static structures that are Doppler-shifted to higher frequencies by the motion of the satellite [Temerin, 1978]. As soon as the satellite enters the bubble, intense electrostatic emissions are recorded in the $\mathrm{kHz}$ frequency range with a clear lowfrequency cut-off. The variations of this low cut-off frequency follow very well the plasma density variations and, 

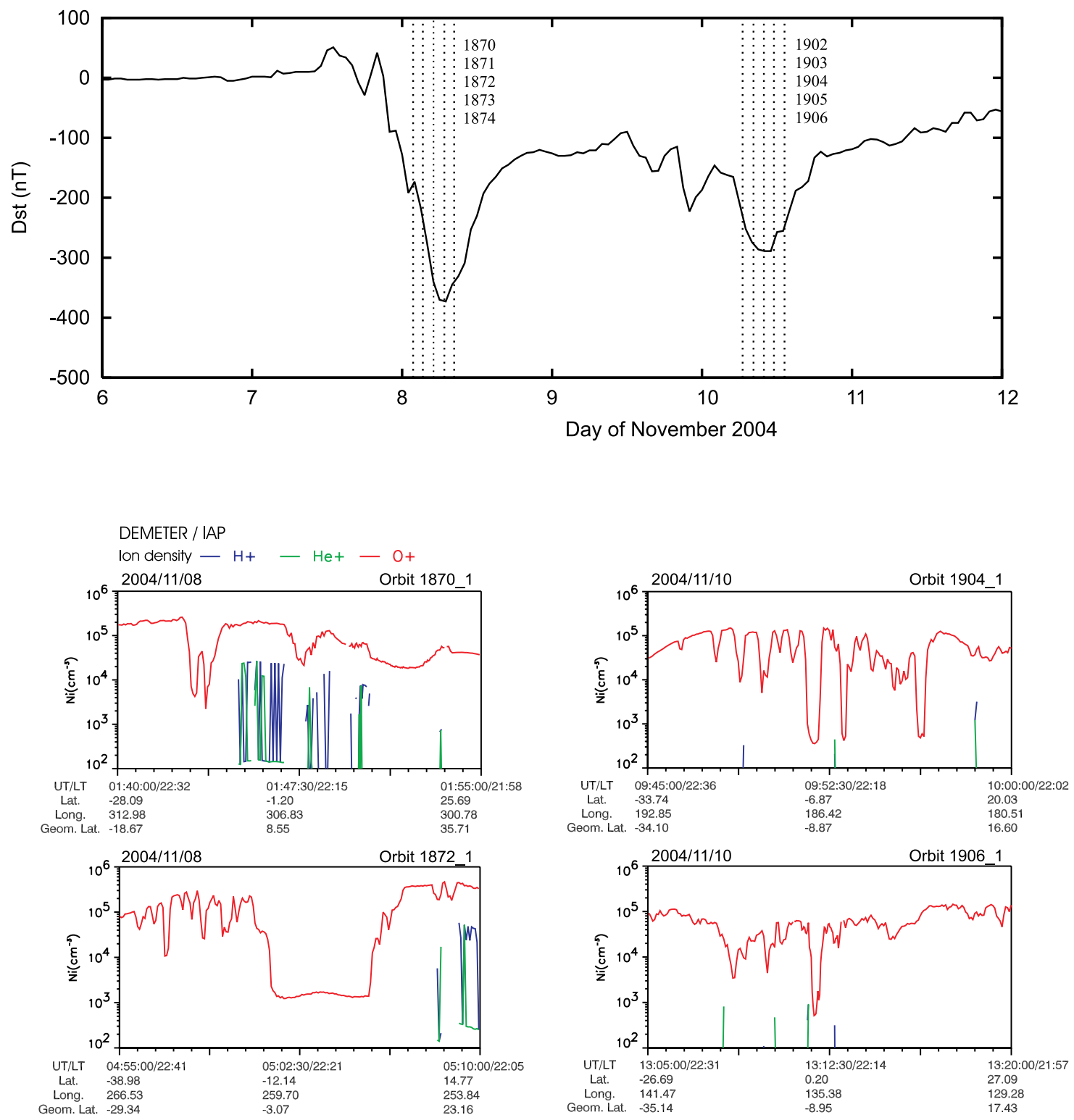

Figure 1. (top) Dst index during 6-11 November 2004; times of the ten orbits during which bubbles and large-scale plasma depletions were observed are indicated by dotted vertical lines (orbit numbers on the right). (bottom) Examples of ion density measurements during the two magnetic storms.

from ion composition measurements, it agrees, within reasonable Doppler shift uncertainties, with the lowerhybrid frequency $\omega_{\mathrm{LH}}$ defined by $\omega_{L H}=\omega_{p e}\left(m_{e} / M_{e f f}\right)^{1 / 2}[1+$ $\left.\left(\omega_{p e} / \omega_{c e}\right)^{2}\right]^{-1 / 2}$. Here $\omega_{p e}, \omega_{c e}, m_{e}$, are the electron plasma frequency, electron gyrofrequency, electron mass, respectively and $M_{\text {eff }}$ the effective mass of the ion mixture defined by $1 / M_{\text {eff }}=\sum \alpha_{i} / M_{i}$, where $\alpha_{i}$ and $M_{i}$ are the relative ion density and the ion mass of the $i$ th ion, respectively. At times of the event, the $\mathrm{E}_{12}$ electric antenna is at large angles $\left(\sim 105^{\circ}\right)$ with respect to $\mathbf{B}_{\mathbf{o}}$ and therefore conveniently oriented to measure lower-hybrid waves with the electric field nearly perpendicular to $\mathbf{B}_{\mathbf{0}}$. The most intense part of this turbulence appears as broadband bursts with the power spectral density at $\omega_{\mathrm{LH}}$ as high as $10^{4} \mu \mathrm{V}^{2} \mathrm{~m}^{-2} \mathrm{~Hz}^{-1}$. Lightning-generated electromagnetic whistlers were systematically observed at the onset of these lower-hybrid emissions. The timescale and evolution are quite similar from one burst to another: emissions are excited within an apparent bandwidth of $\sim 1.5 \mathrm{kHz}$ above the lower-hybrid frequency at the onset, and a regular decrease of this bandwidth is observed in the seconds following the onset while the low cut-off frequency remains close to the lowerhybrid frequency (Figure 3b). The broadband r.m.s. electricfield strength reaches $2-3 \mathrm{mV} \mathrm{m}^{-1}$.

[12] A close examination of the VLF waveforms reveals a new striking and unexpected feature exemplified in Figure 4 which displays a zoomed frequency-time spectrogram (Figure $4 \mathrm{a}$ ) and the associated waveform (Figure $4 \mathrm{~b}$ for the $2 \mathrm{~s}$ period $08: 15: 12: 200$ UT to $08: 15: 14: 200$ UT. Embedded in the more diffuse lower-hybrid electrostatic turbulence are bursts of nearly pure frequency lasting about $20 \mathrm{~ms}$ and with peak amplitudes up to $\sim 15 \mathrm{mV} / \mathrm{m}$ 


\section{DEMETER 2004/11/10 Orbit: 01903 1}
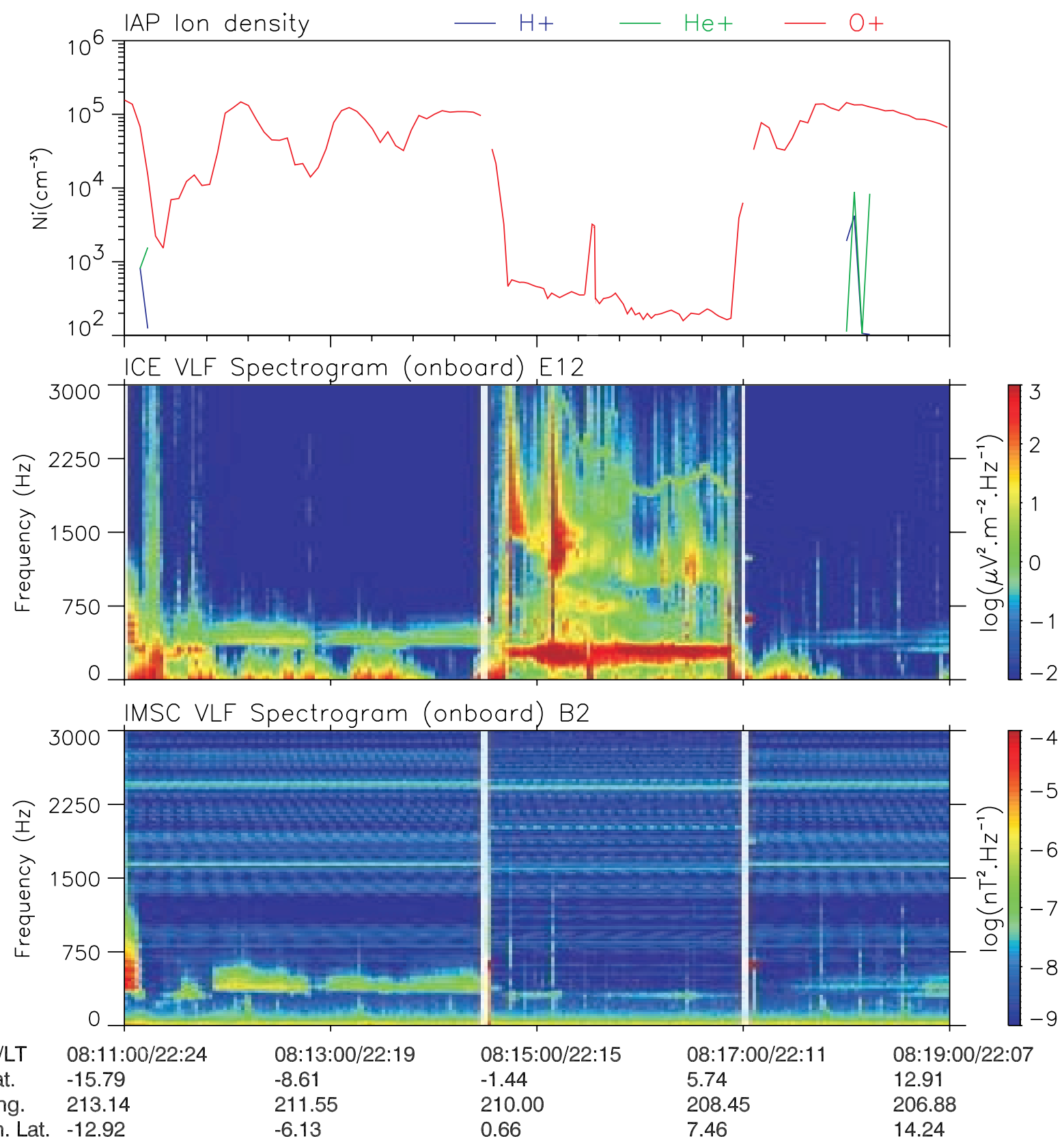

Figure 2. Overview of plasma and low-frequency wave measurements during orbit 1903 _ while the spacecraft orbited above thunderstorm cells in the Pacific region. From top to bottom: ion density (IAP experiment), VLF spectrogram of the electric field component E12 (ICE experiment), and VLF spectrogram of the B2 magnetic field component (IMSC experiment). The data are displayed as function of the universal time (UT), local time (LT), geographic latitude (Lat) and longitude (Long), and the geomagnetic latitude (Geom. Lat.). The white vertical lines in the wave spectrograms delimit the time interval when DEMETER was operated in the burst mode.

(Figure 4c), similar to the lower-hybrid structures that are commonly observed on auroral field lines associated with the discrete aurora. The spectrum of the structure which occurred just after 8:15:13:112 UT exhibits a peak at $1230 \mathrm{~Hz}, 18 \mathrm{~dB}$ larger than the corresponding power spectral density of the diffuse lower-hybrid emissions as measured just before and after the event (Figure 4d). Taking into account the angle between the satellite velocity and the geomagnetic field and assuming a possible motion of the LHSs detected by DEMETER on the order of the ion acoustic velocity, the observed typical time duration of 

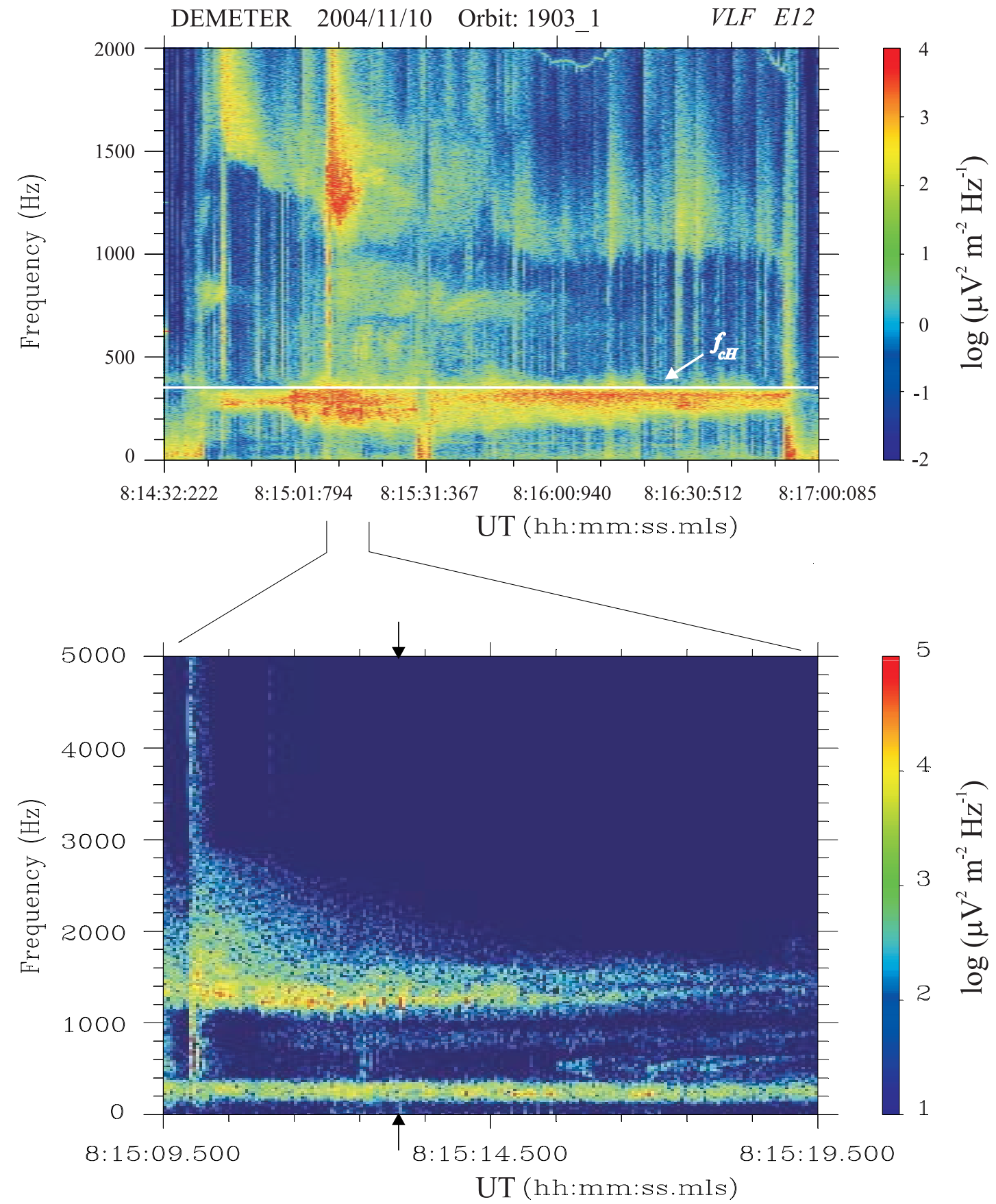

Figure 3. (a) Frequency-Time spectrogram of ELF and VLF waves recorded in the large equatorial plasma density depletion encountered by DEMETER during orbit 1903. (b) Lower-hybrid wave emissions near $1.2 \mathrm{kHz}$ triggered by a lightning-generated spheric near 08:15:09 UT. The arrows on the time axis indicate the lower-hybrid solitary structure shown in Figure 4.

the bursts corresponds to sizes of $\sim 40-70 \mathrm{~m}$ transverse to $\mathbf{B}_{\mathbf{0}}$, i.e., on the order of $6-10 \mathrm{O}^{+}$ion gyroradii.

[13] Besides the lower-hybrid turbulence, the other main feature of the plasma waves is a strong electromagnetic ELF emission in a narrow frequency band below the proton gyrofrequency that is practically continuous throughout the depletion. Figure 5 shows the waveforms of the $E_{x}$ and $B_{y}$ components of the ELF electromagnetic field in a coordinate system linked to the local Earth's magnetic field (the $\mathrm{z}$ axis lies along $\mathbf{B}_{\mathbf{0}}$, the $\mathrm{y}$ axis is perpendicular to the magnetic meridian plane pointing eastward, and the $\mathrm{x}$ axis completes the right-hand coordinate system; at low latitudes the $\mathrm{x}$ axis points approximately in the upward direction). As can be seen, the ELF emission is highly coherent. It takes the form of a continuous wave train of a few $\mathrm{mV} / \mathrm{m}$ amplitude, sometimes similar to a beat-like waveform but most often with an irregular amplitude modulation. The ELF electromagnetic emission is observed from the entry to the exit from the depletion at 8:17:00 UT, except during the crossing of the "bifurcation region" between 8:15:30 UT 


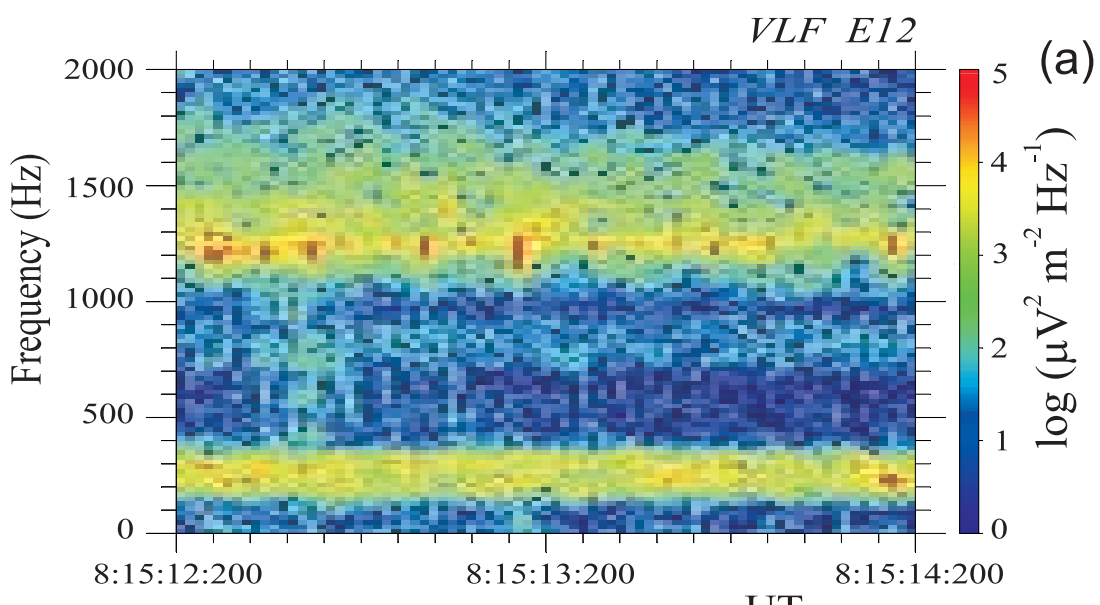

UT

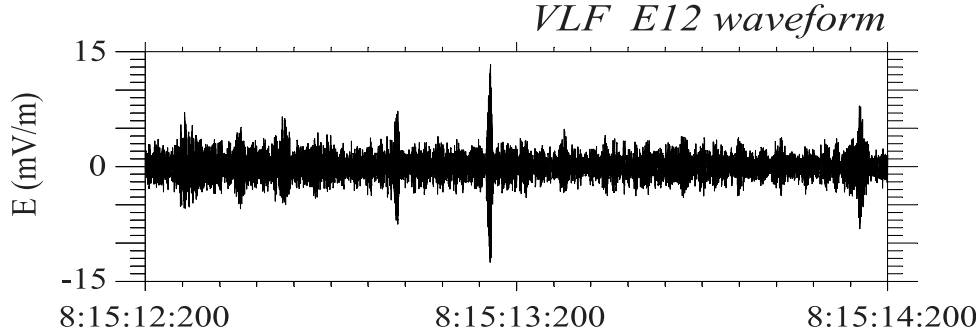

(b)

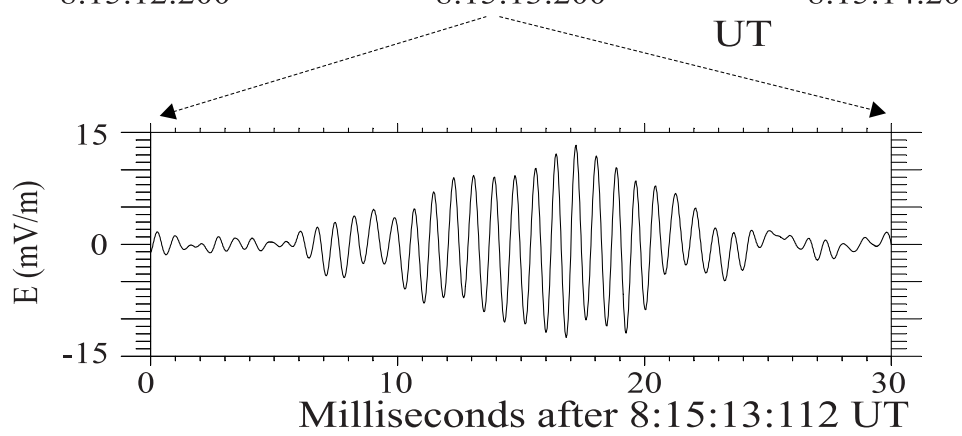

(c)

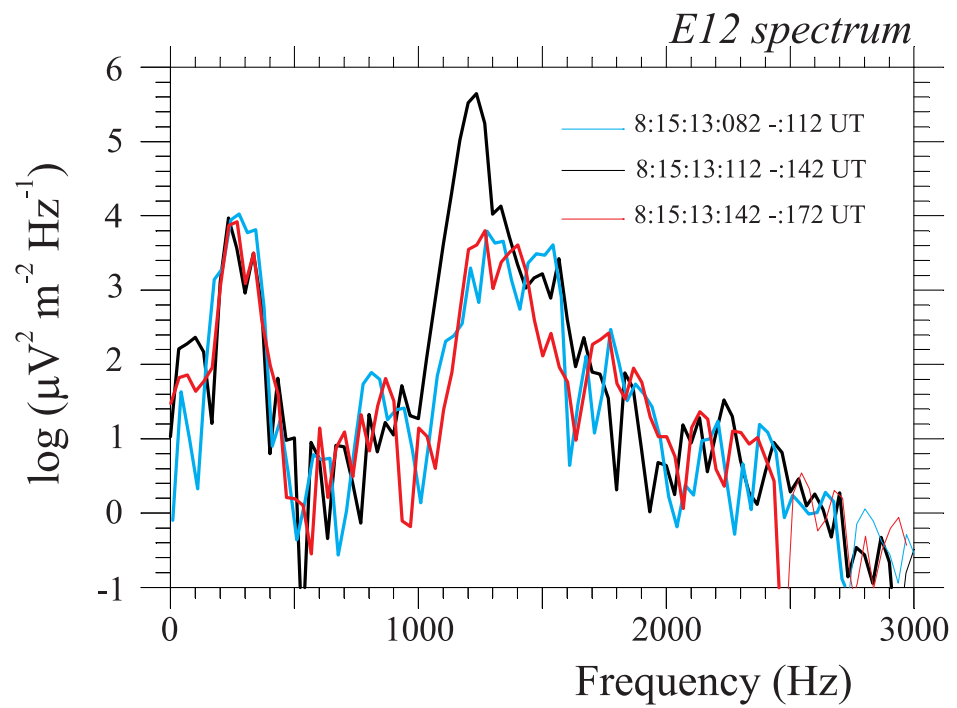

(d)

Figure 4. Wave data showing short bursts of lower-hybrid solitary structures during the event shown in Figure 3b. (a) Frequency-Time spectrogram, (b) associated waveform, and (c) 30-ms zoom of the LHSS event observed at 08:15:13.120 UT. (d) Spectra recorded before (blue), during (black), and after (red) the LHSS event displayed in Figure 4c. 

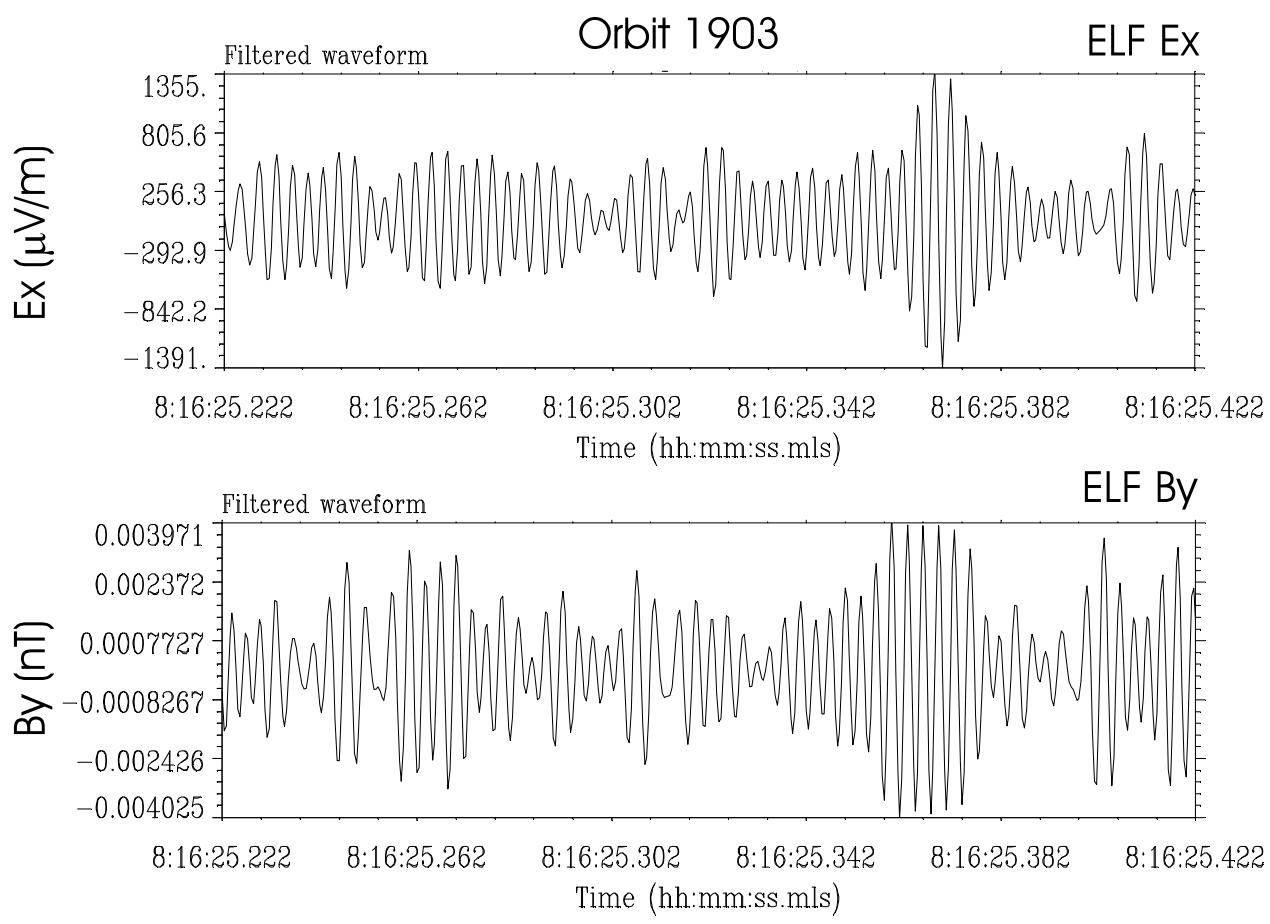

Figure 5. Waveforms of the ELF $E_{x}$ (in the geomagnetic meridian plane and perpendicular to $\mathbf{B}_{\mathbf{o}}$ ) and $B_{y}$ (perpendicular to $\mathbf{B}_{\mathbf{o}}$ in the east-west direction) components showing the coherency of the trapped ELF electromagnetic emissions observed below $\mathrm{f}_{\mathrm{cH}}$ in the depletion. The waveforms have been passband filtered between 200 and $350 \mathrm{~Hz}$.

and 8:15:33 UT where it disappears. Note that the occurrence in this short period of an electrostatic ELF turbulence between 0 and $\sim 300 \mathrm{~Hz}$, similar to that observed at the depletion boundaries strongly supports the bifurcation scheme proposed above. The availability of the waveforms of the six components of the ELF electromagnetic field in the burst mode allows a detailed wave propagation analysis and thus the electromagnetic ELF waves were analyzed using the PRASSADCO multidimensional spectral analysis software [Santolik, 2003]. Figure 6 shows the results. Figures $6 \mathrm{a}-6 \mathrm{~d}$ show the power spectral densities of the $B_{y}$ (much more intense than $\mathrm{B}_{\mathrm{x}}$ and $\mathrm{B}_{\mathrm{z}}$ ) and of the three electric components in the geomagnetic reference frame, respectively. The white (or black), horizontal line in each spectrogram gives the local proton gyrofrequency, $\omega_{\mathrm{cH}}$. Two main spectral lines appear in the power spectra below $\omega_{\mathrm{cH}}$, peaked around $\sim 270 \mathrm{~Hz}$ and $\sim 320 \mathrm{~Hz}\left(\omega / \omega_{\mathrm{cH}} \sim 0.76\right.$ and 0.91 , respectively). Each line has a bandwidth of $\sim 30 \mathrm{~Hz}$ (see the 10 s-averaged spectra at 8:14:54 UT shown in Figure 7). An estimate of the index of refraction deduced from the electric and magnetic power spectral densities measured at 08:14:54 UT yields values of 0.4 at $270 \mathrm{~Hz}$ and 1.5 at $320 \mathrm{~Hz}$. Another intense line is seen between 08:15:00 UT and 8:15:30 UT in the electric-field spectra (see Figure 8) in a frequency band centered around $230 \mathrm{~Hz}$ $\left(\omega / \omega_{\mathrm{cH}} \sim 0.65\right)$. The lack of or the too low intensity of the wave magnetic field for these latter waves precludes a detailed analysis of the propagation characteristics. For the first group of emissions the planarity of polarization of the wave magnetic field calculated by the Singular Value Decomposition (SVD) technique [Santolik, 2003] displayed in Figure 6e, has a value close to 0.8 for the line at $320 \mathrm{~Hz}$, suggesting that the wave field for this line approaches the behavior of a plane wave. These $320 \mathrm{~Hz}$ waves propagate with a $\mathbf{k}$ vector close to the $\mathbf{B}_{\mathbf{0}}$ direction (Figure $6 \mathrm{~g}$ ). This low value of the polar angle $\theta_{\mathrm{B}, \mathrm{k}}$ can induce large uncertainties in the determination of the azimuthal angle $\phi_{\mathrm{B}, \mathrm{k}}$ of the $\mathbf{k}$ vector. Nevertheless, the obtained values of $\phi_{\mathrm{B}, \mathrm{k}}$ (Figure 6h) suggest that the waves propagate approximately in the local magnetic meridian plane; They are characterized by a weakly elliptic polarization in the plane transverse to $\mathbf{B}_{\mathbf{o}}$ (Figure $6 \mathrm{f}$ ). The sense of polarization is not well defined because of large uncertainties caused by random errors of the spectral analysis for a low elliptical polariza-

Figure 6. Analysis of wave data recorded in the ELF burst mode during orbit 1903. The six components of the electromagnetic field have been analyzed using the software PRASSADCO. (a) Power spectrogram of the $B_{y}$ component; (b, c, d) power spectrograms of the $E_{x}, E_{y}$ and $E_{z}$ components, respectively; (e) planarity (a value of 1 corresponds to the presence of a single plane wave); (f) ellipticity (a value of 0 corresponds to a linear polarization and a value of 1 to a circular polarization; the sign defines the polarization sense); (g) polar angle $\left(\mathbf{k}, \mathbf{B}_{\mathbf{o}}\right)$ of the $\mathbf{k}$ vector; (h) azimuthal angle of $\mathbf{k}$ $\left(0^{\circ}\right.$ corresponds to the local magnetic meridian plane); $(\mathrm{i}, \mathrm{j})$ perpendicular and $(\mathrm{k})$ parallel components of the Poynting vector normalized by its standard deviation. The white line in the top panels and the black line in the bottom panels indicate the local proton gyrofrequency. 
tion. The calculation of the parallel (Figure 6k) and perpendicular components (Figures 6i and 6j) of the Poynting vector indicates that the wave energy propagates at large angles with respect to $\mathbf{B}_{\mathbf{0}}$, approximately in the upward (x) direction.
[14] Finally, it is interesting to mention that, for some orbits, bursts of ULF electromagnetic emissions are sometimes detected on the eastern edge of depletions just before the broadband electrostatic turbulence is observed. These ULF emissions are not readily apparent in the spectrogram

Demeter 2004-11-10 08:14:31.222 - 2004-11-10 08:16:58.678

(a)

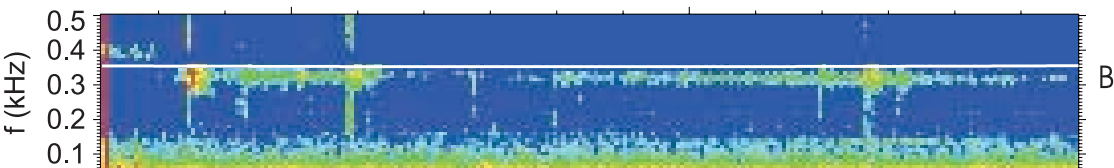

(b)
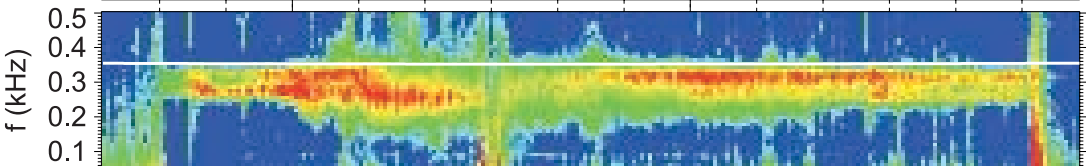

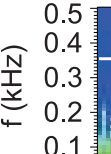
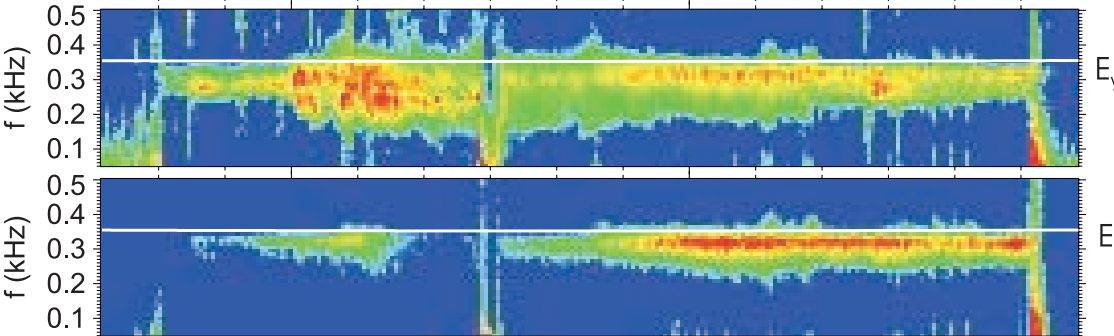

(e)
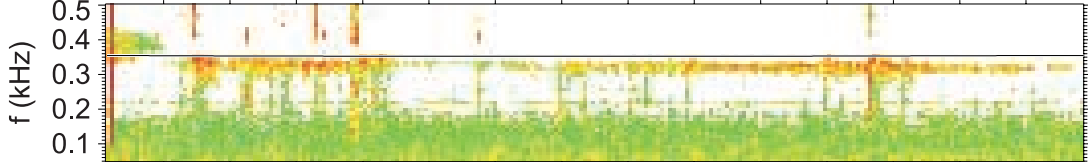

(f)

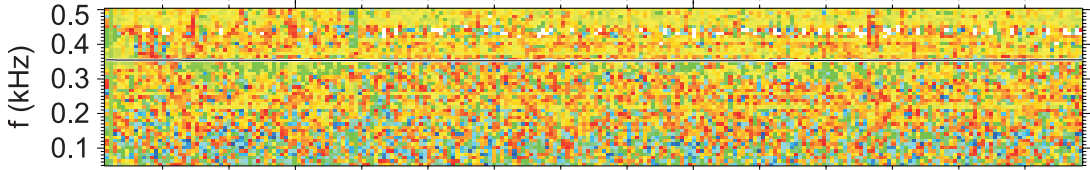

(g)

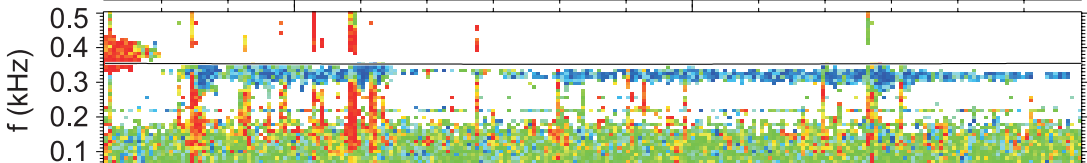

(h)
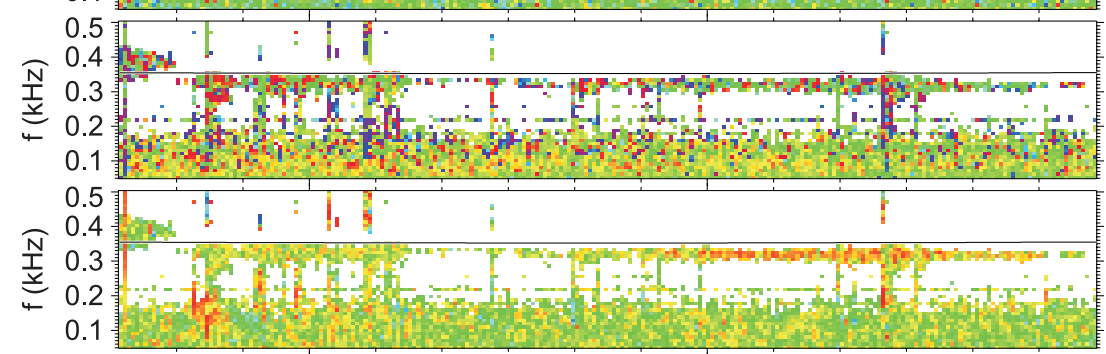

(i)

(j)

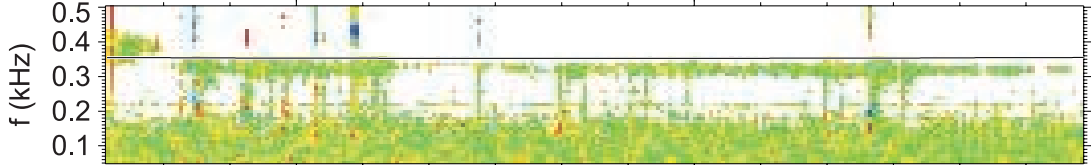

(k)

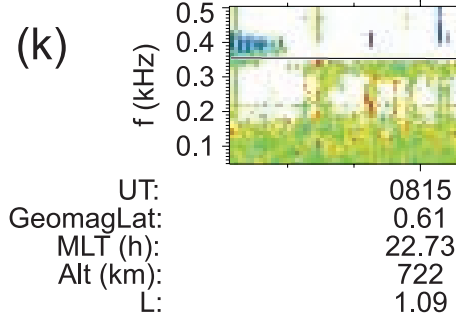

0816

0816
4.04

4.04
22.66

722

1.10

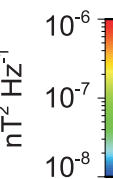

'N $10^{-2}$

N $10^{-3}$

s

है $10^{-4}$

'N $10^{-2}$ 霍

$10^{-3}$

है

$10^{-2}$

N $10^{-3}$

'E

है $10^{-5}$

1.07

के 0.8

言 0.6

ᄃ 0.4

줌 0.2

离 0.5

을 0.0

言

क 90 柾

ब 60

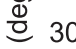

商

๑ 180

\begin{tabular}{rr}
0 & 90 \\
\hline & 0
\end{tabular}

$\begin{array}{ll}0 & -90\end{array}$

商 -180

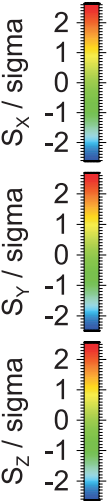

Figure 6 

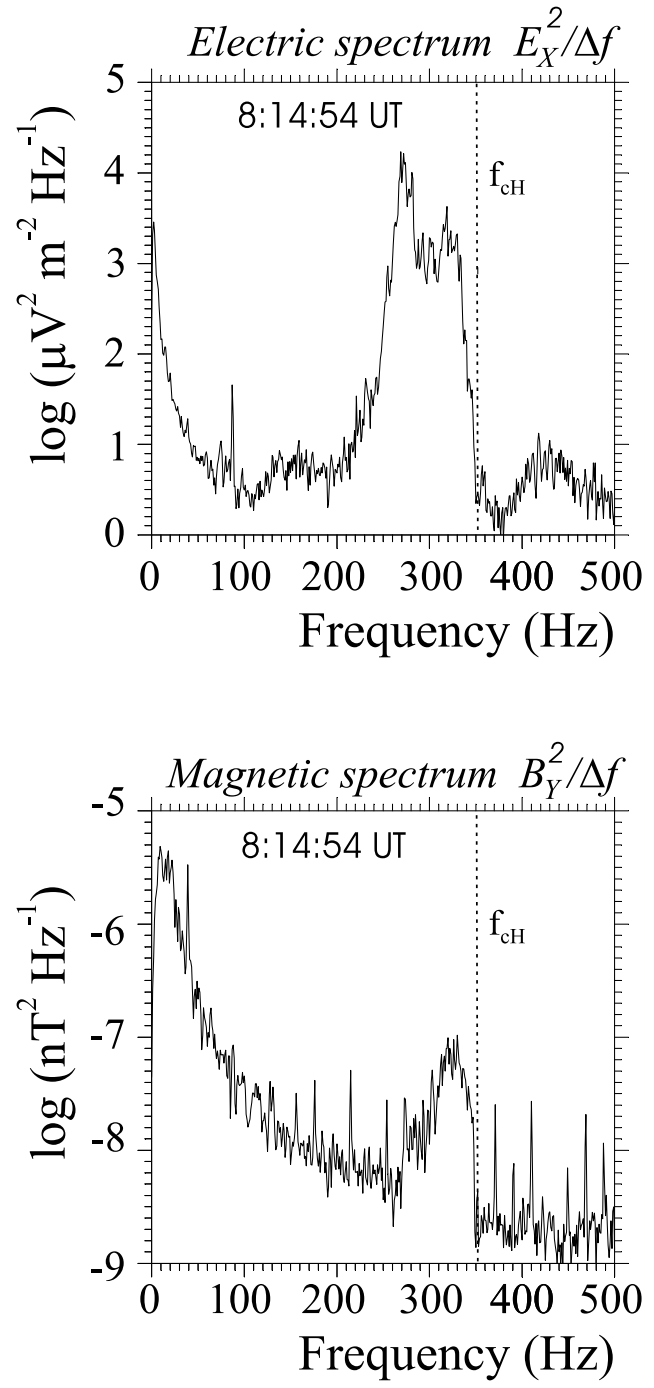

Figure 7. Spectra of the $E_{x}$ and $B_{y}$ components (both perpendicular to $\mathbf{B}_{\mathbf{o}}$ ) measured inside the depletion at 08:14:54 UT.

displayed in Figure 3. This might be explained either by their non-existence for this orbit or by the fact that they might be hidden by the intense electrostatic turbulence occurring on the edges of the depletions. We will not discuss these emissions in the present paper but wish to indicate that they look similar to the Alfvén waves described by Pottelette et al. [2007]. These Alfvén waves carry the field-aligned currents that couple the F-region and the north and south conjugate E-regions during the bubble motion as predicted by previous authors [Aggson et al., 1992; Bhattacharyya and Burke, 2000].

\section{Discussion}

[15] Data from orbit 1903 are representative of observations made by DEMETER within deep equatorial plasma depletions in the pre-midnight sector during intense magnetic storms. This is well illustrated by Figure 9 which displays similar data from two other orbits during the same storm, and Figure 10 showing similar observations made on 15 May 2005 and on 24 August 2005 during the main phase of two other strong magnetic storms (peak Dst $\sim-256 \mathrm{nT}$ and $-219 \mathrm{nT}$, respectively).

[16] During orbit 1902 (Figure 9, top panel), 1 h $40 \mathrm{~min}$ before orbit 1903, the satellite crossed a series of plasma depletions. For three of them (narrow regions at $\sim 06: 32$ : 45 UT and $\sim 06: 33: 15$ UT and a wider depletion between 06:34:40 UT and 06:35:40 UT, labeled a, b, c, respectively), the ion density drops to values as low as $5 \times 10^{2} \mathrm{~cm}^{-3}$, i.e., more than two orders of magnitude than the background value (and even more at 06:36:30 UT). As in orbit 1903, the electric field spectrogram shows the occurrence of impulsive events followed by a broadband turbulence with a lower cutoff at the local lower-hybrid frequency, and, as in orbit 1903, a narrowband band electromagnetic ELF emission below the proton gyrofrequency. It is worthy of note that there is not any signature of such ELF trapped emission in the other not so deep depletions (ion density $\geq 10^{4} \mathrm{~cm}^{-3}$ ) encountered between 06:32:00 UT and 06:32:30 UT (labeled d) and around 06:34:00 UT (labeled e). We also remark that no lower-hybrid turbulence is observed in association with the lightning occurring in depletions $d$
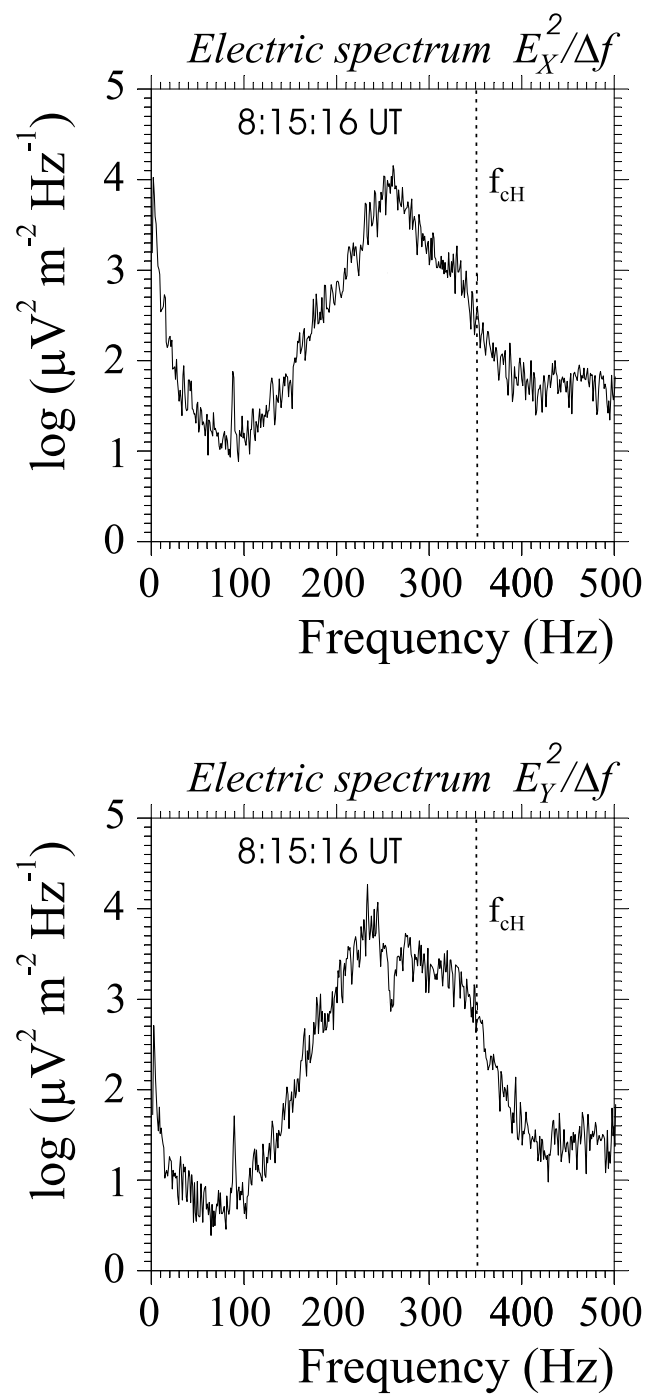

Figure 8. Spectra of the $E_{x}$ and $E_{y}$ components (both perpendicular to $\mathbf{B}_{\mathbf{o}}$ ) measured inside the depletion at 08:15:16 UT. 


\section{DEMETER - 2004/11/10 - Orbit : 1902_1}
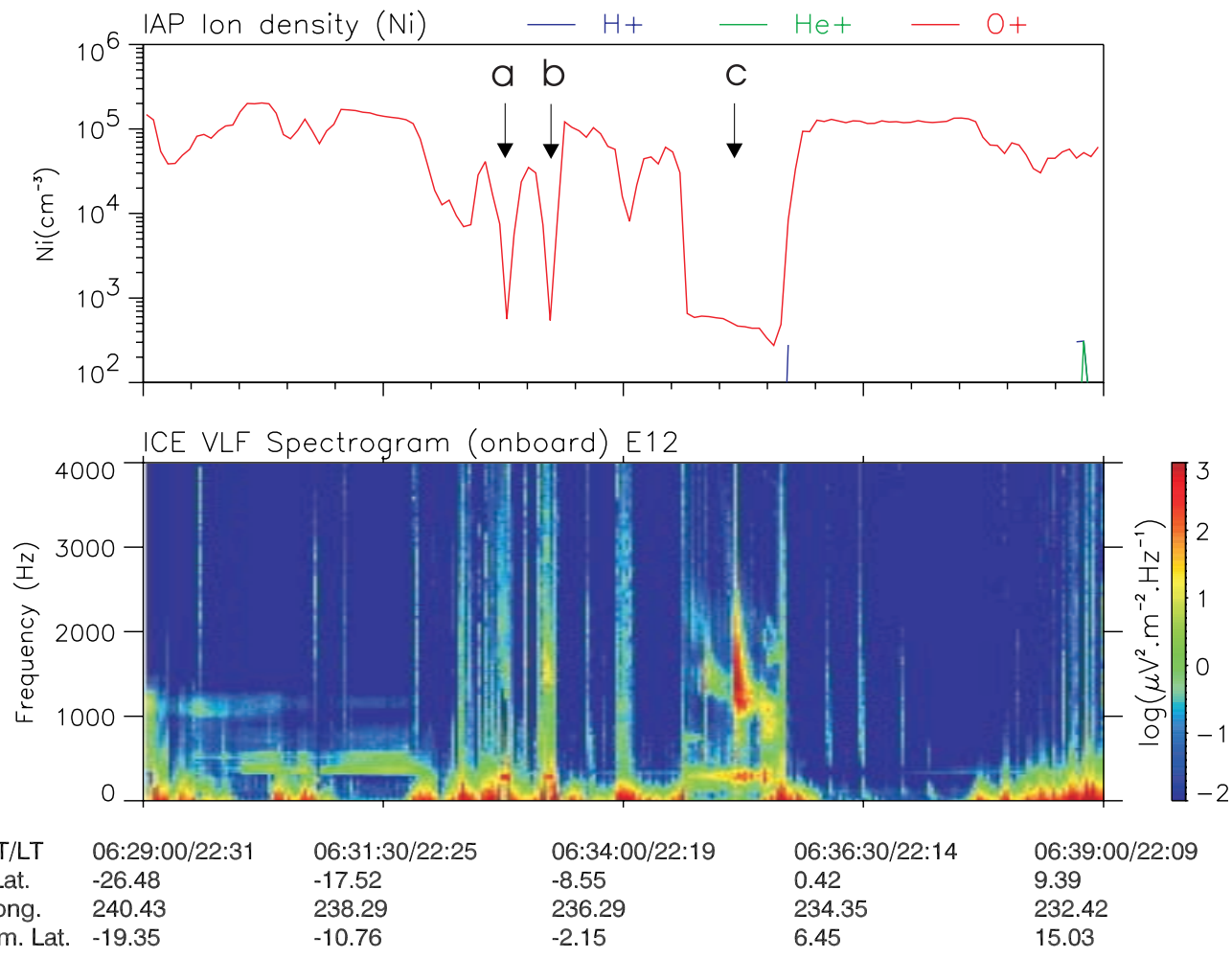

$\begin{array}{clllll}\text { UT/LT } & 06: 29: 00 / 22: 31 & 06: 31: 30 / 22: 25 & 06: 34: 00 / 22: 19 & 06: 36: 30 / 22: 14 & 06: 39: 00 / 22: 09 \\ \text { Lat. } & -26.48 & -17.52 & -8.55 & 0.42 & 9.39 \\ \text { Long. } & 240.43 & 238.29 & 236.29 & 234.35 & 232.42 \\ \text { Geom. Lat. } & -19.35 & -10.76 & -2.15 & 6.45 & 15.03\end{array}$

\section{DEMETER - 2004/11/10 - Orbit : 1905_1}
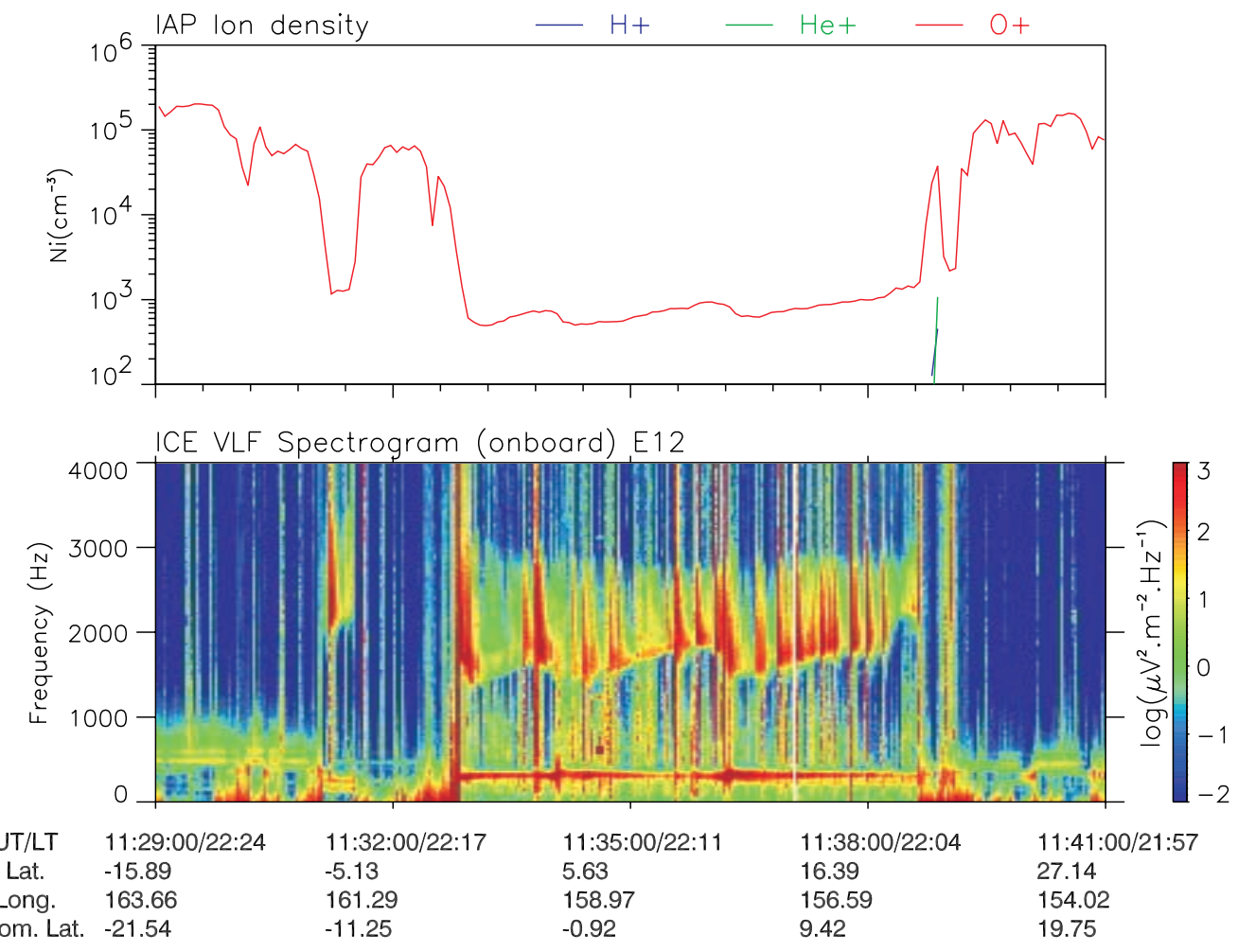

Figure 9. Ion density variations and frequency-time spectrogram of one VLF electric field component measured during orbits 1902 (top panels) and 1905 (bottom panels). 



Figure 10. Ion density variations and frequency-time spectrogram of one VLF electric field component measured during orbit 4610 on 15 May 2005 (top panels) and orbit 6083 on 28 August 2005 (bottom panels). 
and e. Measurements from orbit 1905 (bottom panel of Figure 4) gives another typical example showing clearly the occurrence of both types of waves in small-scale (11:31: 15 UT) and large-scale (between 11:32:40 UT and 11:38: 30 UT) depletions. In view of its longitudinal extent, much wider than those of normal bubbles, the main depletion is likely an example of density dropout structure associated with the uplift of the bottomside ionosphere above the altitude of DEMETER over an extended longitudinal region. We also remark that lightning occurring on either side of the narrow depletion does not trigger lower-hybrid turbulence unlike those occurring inside the depletion.

[17] A summary of the most prominent wave features is as follows:

[18] 1. The triggering of broadband electrostatic lowerhybrid turbulence by lightning in deep depletions where the electron plasma frequency is lower than the electron gyrofrequency. Rocket observations of lower-hybrid waves with similar amplitude and induced by lightning in the troposphere were reported by Kelley et al. [1990] and Baker et al. [2000]. However, the triggered waves observed by these authors lasted for about 10-20 ms, whereas the lowerhybrid emissions recorded by Demeter in the depletions have typical duration of 5-10 s. Besides this large difference, which apparently is linked to strongly different plasma conditions (much denser plasma in the rocket experiments), the main interesting feature in the Demeter observations is the fact they reveal, for the first time, that this lower-hybrid turbulence may evolve into structures similar to lowerhybrid structures commonly observed along auroral field lines.

[19] 2. The occurrence of intense narrowband electromagnetic ELF emissions at frequencies below the proton gyrofrequency that appear to be trapped within the depletions.

\subsection{Lower-Hybrid Emissions}

[20] The events occurred during thunderstorm periods and their close association with lightning lead us to consider two possible mechanisms that might be involved in the generation of the lower-hybrid turbulence: either a rapidly growing plasma instability triggered by the transient largeamplitude pulse of the whistler electric field or the scattering of lightning-induced electromagnetic whistlers from pre-existing density irregularities. The former mechanism has been proposed by Kelley et al. [1984] to explain sudden increases in the backscattered radar signals ("explosive spread F events") correlated with intense lightning discharges in the lower atmosphere. Owing to their larger mass, the ions respond more slowly than electrons to the electric field pulse; the resulting perpendicular Hall current induced by the $\mathbf{E} \times \mathbf{B}$ drift in a time period shorter than the ion gyro-period drives a two-stream instability which generates lower-hybrid waves. Several arguments can be put forward against this explanation. These transient E-fields last typically about $10-20 \mathrm{~ms}$ and their amplitude may reach a few tens of $\mathrm{mV} / \mathrm{m}$, which leads to a drift velocity $\mathrm{v}_{\mathrm{D}} \sim 1-2$ times the ion thermal velocity for $0.1 \mathrm{eV} \mathrm{O}^{+}$ions. This value is close to the threshold velocity for instability and values of the associated growth rate are small. However, above all, the maximum growth rate depends on the plasma density as $n^{1 / 2}$. The growth rate of the instability in regions of very low density as in the plasma density depletions observed by DEMETER is very low, thus ruling out this mechanism. The observations of intense electromagnetic whistlers generated from tropospheric lightning discharges occurring beneath the satellite at the onset of the diffuse and wideband LH turbulence strongly support the second mechanism, based upon scattering or mode conversion of whistlers by pre-existing small-scale electron density irregularities with scale sizes of the order of the wavelength of the lower-hybrid waves [Bell and Ngo, 1990]. This model assumes the pre-existence inside the bubble of plasma irregularities at small scales, typically on the order of a few meters to several tens of meters for an $\mathrm{O}^{+}$-dominated plasma with a temperature of $\sim 0.1 \mathrm{eV}$. Plasma data shown in the papers by Berthelier et al. (manuscript in preparation, 2008) do show the existence of small-scale irregularities at scales of $\sim 40 \mathrm{~m}$ along the orbit, corresponding to $\sim 10 \mathrm{~m}$ perpendicular to $\mathbf{B}_{\mathbf{o}}$

[21] The discovery of LHSs inside equatorial plasma bubbles is at first sight very surprising and raises many questions. As mentioned in the introduction, similar LHSs are omnipresent in the auroral zone, and are often correlated with small-scale density depletions of a few \%. Some examples of density depletions simultaneous with LHSs observed during the DEMETER orbit 1903 are reported in the companion paper [Berthelier et al., 2008], in particular at $08: 15: 13: 130 \mathrm{UT}(\delta \mathrm{n} / \mathrm{n} \sim 8 \%)$, but more observations are needed to draw a definite conclusion. The plasma and energetic particle conditions in the equatorial ionosphere are widely different from those prevailing on auroral field lines. This raises in particular the question of the possible source of free energy and/or of the physical mechanism able to give rise to such structures.

[22] Wave packet localization due to strong turbulence processes has often been invoked to explain the lowerhybrid structures observed in the auroral zone as the consequence of the modulational instability and collapse of lower-hybrid waves produced by energetic auroral electrons [Shapiro et al., 1993]. Nevertheless, this explanation is very controversial because of discrepancies between characteristics of the structures inferred from statistical analyzes of data and those predicted by the collapse theory. For $\omega_{\text {ce }} \gg \omega_{\text {pe }}$, the relevant condition within plasma bubbles, and assuming $T_{e} \sim T_{i}$, the threshold for wave collapse is given by [Robinson et al., 1996]

$$
E_{\perp} l_{\perp}>\alpha\left(\frac{m_{e}}{m_{i}}\right)^{1 / 2} \frac{\omega_{c e}}{\omega_{p e}} \frac{k_{B} T_{e}}{e}
$$

where $E_{\perp}$ and $l_{\perp}$ are the maximum electric field and the perpendicular scale (half width at half maximum) of the wave structure, respectively, $k_{B} T_{e} / e$ is the electron energy in $\mathrm{eV}$, and $\alpha$ a numerical coefficient of the order of 20. For the event shown in Figure 4, the plasma density $\mathrm{n}=3.2 \times$ $10^{2} \mathrm{~cm}^{-3}, \omega_{c e} / \omega_{p e}=3.96, k_{B} T_{e} / e \approx 0.1 \mathrm{eV}$; thus taking $l_{\perp} \approx$ $10 \mathrm{~m}$, we get for an $\mathrm{O}^{+}$plasma a theoretical threshold $\mathrm{E}_{\perp} \approx$ $5 \mathrm{mV} / \mathrm{m}$. The $15 \mathrm{mV} / \mathrm{m}$ electric field observed for this event exceeds the collapse threshold. However, for most of events, the measured electric fields are below the collapse threshold estimated to $3 \mathrm{mV} / \mathrm{m}$ to $6 \mathrm{mV} / \mathrm{m}$ on the basis of density measurements within the depletions. Therefore the moderate amplitude of the electric field in most of observed LHSs tends not to support the wave collapse model. 

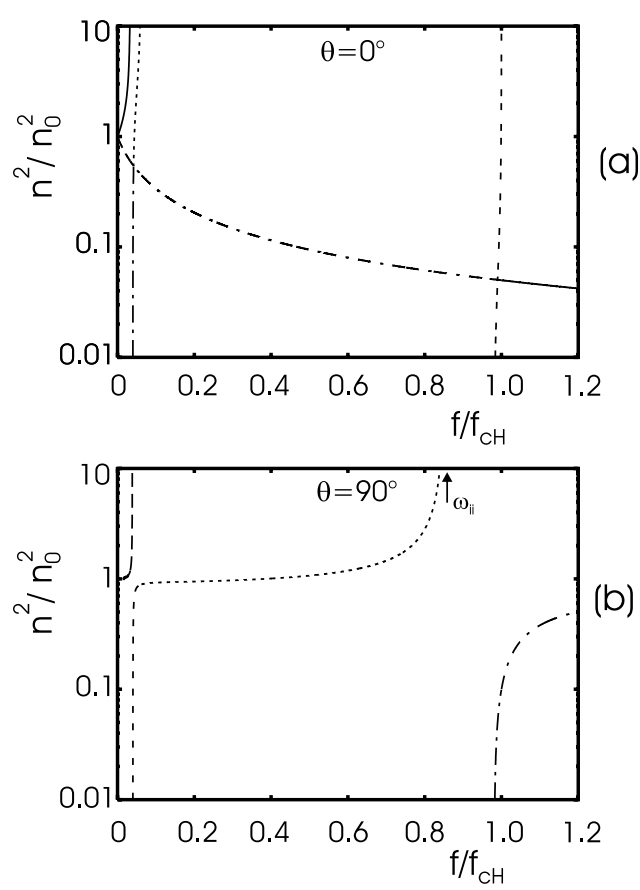

Figure 11. Dispersion curves of waves propagating (a) parallel and (b) perpendicular to $\mathbf{B}_{\mathbf{o}}$. The plasma parameters are representative of the plasma within the large depletion in orbit 1903. $\mathrm{n}_{0}$ is the value of the refractive index for $\omega=0$ and $\theta=0$, given by $\left[1+\sum\left(\omega_{\mathrm{ps}} / \omega_{\mathrm{cs}}\right)^{2}\right]^{1 / 2}$, where $\omega_{\mathrm{ps}}$ and $\omega_{\mathrm{cs}}$ are the plasma frequency and the gyrofrequency of species $\mathrm{s}(\mathrm{s}=\mathrm{e}, \mathrm{i})$, respectively.

Furthermore, the value of the predicted collapse time is shorter than the observed time duration of the LHSs, which also argues against the strong turbulence explanation. It is worthy of note that results of a study by Schuck et al. [2002], based on the statistical properties of LHSs observed in the auroral ionosphere, do not support the modern theory of strong turbulence, based on a four phase nucleation cycle [Robinson, 1999], as an explanation for LHSs.

[23] Schuck et al. [1998] proposed an interpretation of LHSs observed in the auroral zone in terms of rotating eigenmodes of a cylindrical, magnetic-field aligned density depletion. The mechanism is based on the conversion of the ambient whistler-mode emissions into short wavelength electrostatic trapped modes on the density gradient at the edge of the density depletion by a linear scattering process. Schuck and Bonnell [2003] have demonstrated that the correct, local dispersion relation for lower-hybrid waves propagating in a plasma density inhomogeneity includes the electron Hall term involving the density gradient. The Hall current produced by the electron $\delta \mathbf{E} \times \mathbf{B}_{\mathbf{o}}$ drift across the density gradient dramatically affects the dispersive characteristics of lower-hybrid waves, and most of the spectral properties of LHSs are quantitatively predicted when including the Hall effect. This mechanism of localization and enhancement of whistler/lower-hybrid waves in lowerhybrid structures is general. The structure of the eigenmodes depends on the geometry of the plasma depletion. The observed similarity between the characteristics of the LHSs detected by DEMETER at the equator and the auroral LHSs lead us to believe that both of them have the same underlying physics. In both cases, the structures are observed in regions of VLF whistler noise occurrence and in highly inhomogeneous underdense plasmas $\left(f_{p e}<f_{c e}\right)$. Even if the energy source of the hiss is different (electromagnetic energy released in lightning discharges for the hiss observed in equatorial depletions and energetic electron beams in the auroral zone), the ingredients required by the mechanism proposed by Schuck et al. [1998], i.e., VLF hiss and density irregularities, are found inside bubbles. The LHSS events observed by Demeter appear thus consistent with a mechanism involving the linear mode conversion of lightning-generated whistler waves to cavity eigenmodes. The new DEMETER observations show that the generation of LHSs is a phenomenon appearing in very different plasma environments and thus lend credence to the idea that LHSs are a fundamental feature of VLF whistler mode turbulence in inhomogeneous, magnetized space plasmas as suggested by Schuck et al. [2003]. Further work and analysis of many events are needed to confirm this interpretation.

[24] Observations from sounding rocket experiments in the topside auroral ionosphere have revealed that LHSs are often associated with ion energization perpendicular to $\mathbf{B}_{\mathbf{o}}$ [Lynch et al., 1999]. Berthelier et al. [2008] have indeed shown that suprathermal ions are detected in the period of occurrence of the LHSs, with densities a few $\%$ of the thermal ions and temperatures of a few eV (i.e., about 1530 times the thermal ion temperature) consistent with iontail heating.

\subsection{Electromagnetic ELF Emissions}

[25] The ELF emissions are clearly electromagnetic waves with a power spectrum of the magnetic component peaking at $3 \times 10^{-7} \mathrm{nT}^{2} / \mathrm{Hz}$ at $320 \mathrm{~Hz}$, thus more than an order of magnitude above the background. This rules out most possible spurious electrostatic signals generated by the interaction of the spacecraft with the ambient plasma. The observations performed at high latitudes in winter in similarly low-density plasmas never showed any emissions similar to those detected in the equatorial plasma depletions.

[26] The plasma data do not show evidence of the presence of light ions $\mathrm{H}^{+}$and $\mathrm{He}^{+}$. This is not surprising since the plasma in the depletion rises from the bottomside F-region where only $\mathrm{O}^{+}$and molecular ions are present. Searching for a possible origin of the ELF emissions one can, at first glance, think of ion-ion frequencies that lie in the same frequency range for the usual multicomponent ionospheric plasma. Nevertheless, since the sensitivity threshold of the plasma analyzer with respect to minor ions is about $\sim 2 \%$ of the density of the major $\mathrm{O}^{+}$and molecular ions, we have considered a plasma consisting of $\mathrm{O}^{+}\left(\alpha_{\mathrm{O}+}=0.75\right)$, $\mathrm{NO}^{+}\left(\alpha_{\mathrm{NO}+}=0.23\right)$ as measured, with an added population of $\mathrm{H}^{+}\left(\alpha_{\mathrm{H}^{+}}=0.02\right)$. Plotted in Figure 11 are the corresponding dispersion curves of waves propagating in (1) a direction quasi-parallel and (2) perpendicular to $\mathbf{B}_{\mathbf{0}}$. The frequencies of the ELF waves measured by Demeter are well below the largest crossover frequency, $\omega_{c r}$, and below the largest lefthand mode cut-off frequency $\omega_{L=0}$ (both of which are close to the proton gyrofrequency) and therefore lie in a frequency range where only the right-hand polarized mode can propagate in an unbounded plasma. There is one ion-ion hybrid 


\section{DEMETER $\quad$ Date ${ }_{(y / m / d)}: 2004 / 11 / 10 \quad$ Orbit: 01903_1}
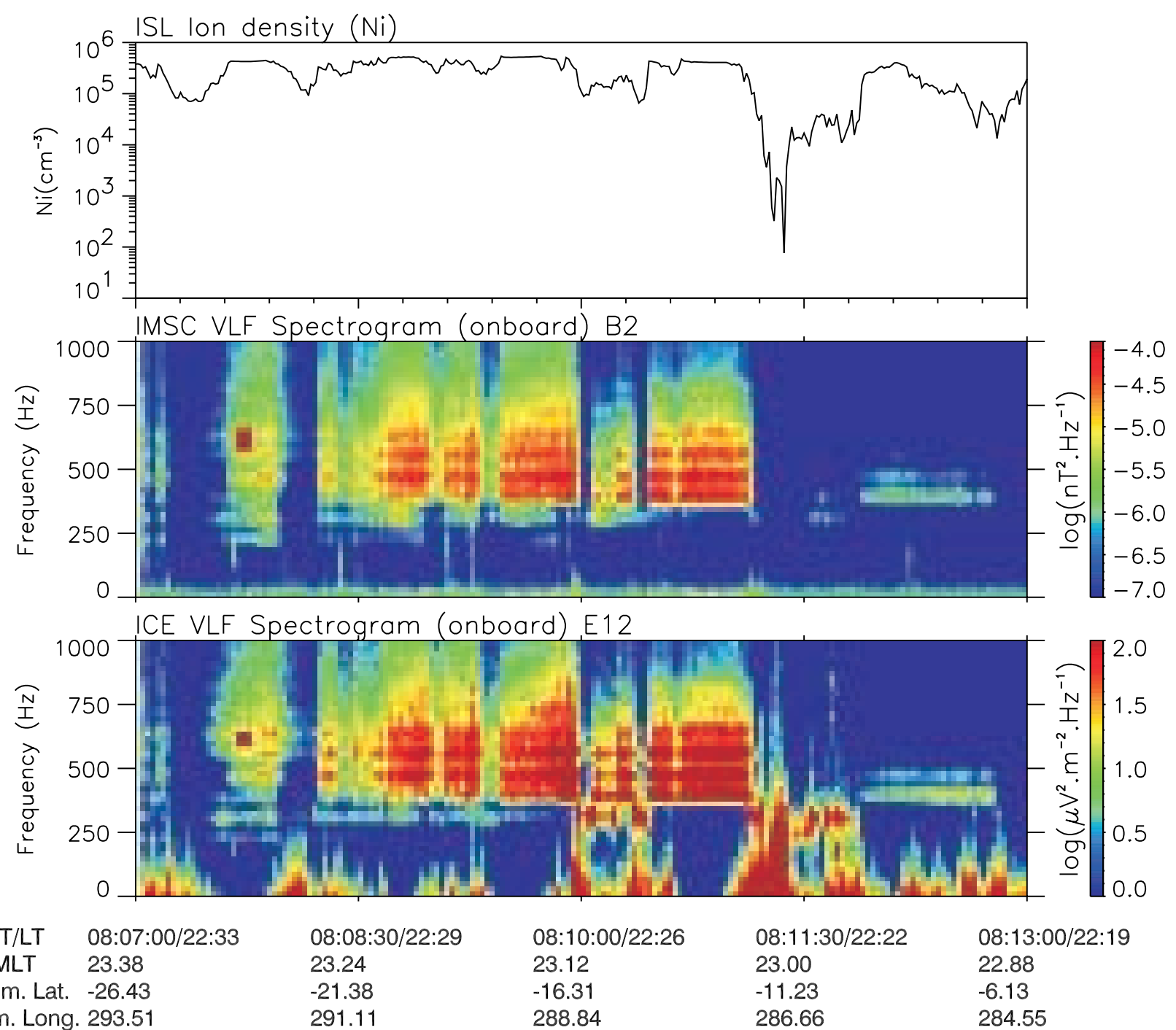

Figure 12. Magnetospheric line radiation events observed at low latitudes during orbit 1903 but outside the large depletion.

frequency in this range (Figure $11 \mathrm{~b} ; \omega_{\mathrm{ii}} \sim 0.86 \omega_{\mathrm{cH}}$ ). Of course, this resonance frequency cannot explain the observed electromagnetic waves propagating almost parallel to $\mathbf{B}_{\mathbf{0}}$ (upper line in Figure 7). Its value is also too high to correspond to waves at $230 \mathrm{~Hz}$ seen in the electric field data (Figure 8 ). Therefore the hypothesis of ion-ion hybrid emission can be ruled out.

[27] Is there some relationship between these intense emissions and the less intense spectral lines of quasiconstant frequency lasting for several minutes that are observed at mid latitudes? These harmonic lines are clearly visible on the frequency-time spectrograms displayed in Figures 2 and 12 at frequencies between $\sim 200 \mathrm{~Hz}$ and $\sim 750 \mathrm{~Hz}$ and appear to belong to the class of "magnetospheric line radiations" (MLRs) that have been observed both on ground and on satellite experiments over the past three decades [Helliwell et al., 1975; Rodger et al., 1995, 2000; Parrot et al., 2006]. Such lines are systematically observed by DEMETER during strong magnetic storms, most often at frequencies below $1.5-2 \mathrm{kHz}$ at mid geomagnetic latitudes and below $1 \mathrm{kHz}$ at low latitudes [Nemec et al., 2007]. They differ in many ways from Power Line Harmonic Radiation (PLHR): PLHR emissions that have their initiating source in power line systems, have frequency spacing of $50 / 100$ or $60 / 120 \mathrm{~Hz}$, occur during both quiet and highly disturbed periods, and are observed mostly at frequencies between $2 \mathrm{kHz}$ and $3 \mathrm{kHz}$. Over most of the orbit, the wave experiments worked in the "survey mode", and therefore only spectra of one magnetic and of one electric components with a frequency resolution of $19.25 \mathrm{~Hz}$ are available to search for a possible link between the MLRs and the ELF emissions in the depletions. The results are shown in Figure 13 which displays (a) magnetic and (b) electric power spectra at different times during orbit 1903_1. Up to nine lines with a frequency spacing of $\sim 80 \mathrm{~Hz}$ appear in the spectra measured at 08:07:45 UT while the satellite was at latitude of $-24^{\circ} \mathrm{S}$ (black lines), well outside the plasma depletion. Clearly the emission observed at $\sim 320 \mathrm{~Hz}$ in 

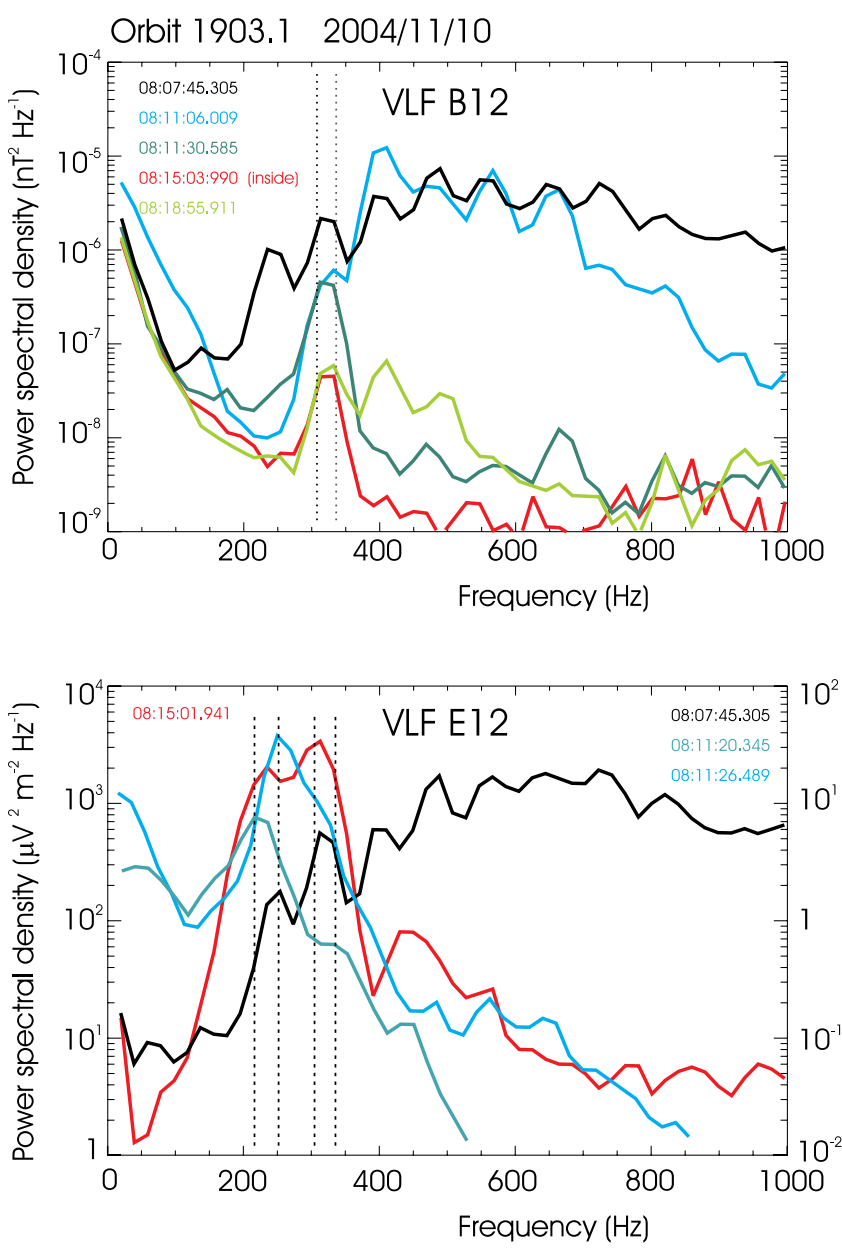

Figure 13. Power spectra of (a) one magnetic and (b) one electric component measured in the survey mode (frequency resolution of $19.25 \mathrm{~Hz}$ ) at different times outside and inside the large-scale depletion during orbit 1903.

the depletion corresponds to one of the harmonic MLRs seen outside. This line is also observed in the less extended depletion encountered around 8:11:30 UT. The emission at $\sim 235 \mathrm{~Hz}$ seen in the depleted plasma regions between 08:15:00 UT and 8:15:30 UT and also just before $8: 11: 30$ UT in the electric spectra is also observed before 08:08:00 UT outside the depletions. We remark that outside the depletions the lines at frequencies above the proton gyrofrequency are the most intense. Lines observed in the large depletions are only observed at frequencies below the proton gyrofrequency. It is also worthy of note that the emissions at $\sim 320 \mathrm{~Hz}$ as well as at $\sim 235 \mathrm{~Hz}$ have their electric field component strongly amplified in the depletions unlike the magnetic component that is less intense, in comparison with the levels observed outside.

[28] The harmonic frequencies and the high intensity of the emissions are suggestive of resonant cavity eigenmodes, where the walls of the cavity are formed by the north-south, east-west, and altitude dimensions of the plasma density depletion. Standing modes between cavity walls occur approximately at frequencies for which a multiple integer of a half-wavelength fits the length, height and width of the cavity. However, the discrete frequencies observed during a single orbit are found to remain constant from depletion to depletion while the dimensions of these depletions vary greatly (for instance, in orbit 1903 the $320 \mathrm{~Hz}$ line is observed at 8:11:30 UT in a small-size depletion as well as in the large-scale depletion crossed 3 min later). Thus the resonant cavity mode model cannot explain the observations and MLRs appear to be the only reasonable explanation.

[29] The origin of these MLRs is still unknown. The most probable explanation is that they are generated at low $\mathrm{L}$ values in the equatorial plane of the inner magnetosphere by unstable particle distribution functions and propagate from their source region down to the ionosphere. Assuming that they are generated at multiples of the local proton gyrofrequency, and considering a frequency spacing of $80 \mathrm{~Hz}$ as observed in orbit 1903, we find a generation source located at $\mathrm{L}=1.8$. Much work remains to be done to confirm this and to understand whether propagation effects and/or ducting and trapping in the density depletions explain why lines at frequencies below the proton gyrofrequency are amplified compared to what happen outside of the depletions.

\section{Conclusions}

[30] The observations presented in this paper provide a general overview of the VLF and ELF emissions detected by DEMETER in deep equatorial plasma density depletions that occur during intense magnetic storms. They reveal that the lightning activity during intense tropospheric storms may produce significant effects in the equatorial ionosphere. Intense, broadband electrostatic lower-hybrid turbulence is triggered by electromagnetic waves associated with lightning events in the troposphere. The most salient and surprising discovery is the occurrence of lower-hybrid structures. The DEMETER data have thus put in evidence for the first time, that plasma processes typical of the auroral ionosphere such as the generation of lower-hybrid structures also occur on equatorial field lines in highly disturbed conditions. To our knowledge, no similar wave observations have thus far been reported. These new findings provide evidence of a new and efficient coupling between the troposphere and the equatorial ionosphere where part of the electromagnetic energy generated by lightning is converted through a series of plasma-wave interactions to kinetic energy of ionospheric ions in the form of a superthermal tail in the ion distribution function. The measurements also reveal the occurrence of intense, narrowband electromagnetic ELF emissions trapped in the density depletions. Our analysis suggests that that these emissions belong to the class of emissions called "MLRs" that are observed elsewhere in the ionosphere and, in particular, by DEMETER over a wide latitudinal range and with a peak of intensity and occurrence during magnetically disturbed periods.

[31] Acknowledgments. This work was supported by funding from CNES under DEMETER/736/7621 grants from 1999 to 2004. J.J. was supported by the Windows-on-Europe-Program at the Air Force Office of Scientific Research.

[32] Amitava Bhattacharjee thanks the reviewers for their assistance in evaluating this paper.

\section{References}

Aggson, T. L., W. J. Burke, N. C. Maynard, W. B. Hanson, P. C. Anderson, J. A. Slavin, W. R. Hoegy, and J. L. Saba (1992), Equatorial plasma bubbles updrafting at supersonic speeds, J. Geophys. Res., 97(A6), $8581-8590$. 
Arnoldy, R., K. Lynch, P. M. Kintner, J. Vago, S. Chesney, T. E. Moore, and C. J. Pollock (1992), Bursts of transverse ion acceleration at rocket altitudes, Geophys. Res. Lett., 19(4), 413-416.

Baker, S. D., et al. (2000), Generation of electrostatic emissions by lightning-induced whistler-mode radiation above thunderstorms, J. Atmos. Sol.-Terr. Phys., 62, 1393-1404.

Basu, S., S. Basu, K. M. Groves, H.-C. Yeh, S.-Y. Su, F. J. Rich, P. J. Sultan, and M. J. Keskinen (2001), Response of the equatorial ionosphere in the South Atlantic region to the great magnetic storm of July 15, 2000 Geophys. Res. Lett., 28(18), 3577-3580, doi:10.1029/2001GL013259.

Bhattacharyya, A., and W. J. Burke (2000), A transmission line analogy for the development of equatorial plasma bubbles, J. Geophys. Res., 105(A11), 24,941-24,950.

Bell, T. F., and H. D. Ngo (1990), Electrostatic lower hybrid waves excited by electromagnetic whistler mode waves scattering from planar magneticfield-aligned plasma density irregularities, J. Geophys. Res., 95(A1), $149-172$.

Berthelier, J. J., et al. (2006a), ICE, the electric field experiment on DEMETER, Planet. Space Sci., 54, 456-471.

Berthelier, J. J., M. Godefroy, F. Leblanc, E. Seran, D. Peschard, P. Gilbert, and J. Artru (2006b), IAP, the thermal plasma analyzer on DEMETER, Planet. Space Sci., 54, 487-501.

Berthelier, J. J., M. Malingre, R. Pfaff, E. Seran, R. Pottelette, J. Jasperse, J. P. Lebreton, and M. Parrot (2008), Lightning-induced plasma turbulence and ion heating in equatorial ionospheric depletions, Nature Geosci., 101-105, doi:10.1038/ngeo109.

Bonnell, J. W., P. W. Schuck, J. L. Pinçon, C. E. Seyler, and P. M. Kintner (1998), Observation of bound states and counterrotating lower hybrid eigenmodes in the auroral ionosphere, Phys. Rev. Lett., 80(26), 5734-5737.

Dovner, P. O., A. I. Eriksson, R. Boström, B. Holback, J. Waldemark, L. Eliasson, and M. Boehm (1997), The occurrence of lower hybrid cavities in the upper ionosphere, Geophys. Res. Lett., 24(5), 619-622.

Eriksson, A., B. Holback, P. Dovner, R. Boström, G. Holmgren, M. André, L. Eliasson, and P. Kintner (1994), Freja observations of correlated smallscale density depletions and enhanced lower hybrid waves, Geophys. Res. Lett., 21(17), 1843-1846.

Greenspan, M. E., C. E. Rasmussen, W. J. Burke, and M. A. Abdu (1991), Equatorial density depletions observed at $840 \mathrm{~km}$ during the great magnetic storm of March 1989, J. Geophys. Res., 96(A8), 13,931-13,942.

Helliwell, R. A., J. P. Katsufrakis, T. F. Bell, and R. Raghuram (1975), VLF line radiation in the earth's magnetosphere and its association with power system radiation, J. Geophys. Res., 80(31), 4249-4258.

Huang, C. Y., W. J. Burke, J. S. Machuzak, L. C. Gentile, and P. J. Sultan (2001), DMSP observations of equatorial plasma bubbles in the topside ionosphere near solar maximum, J. Geophys. Res., 106(A5), 8131-8142.

Kelley, M. C. (1989), The Earth's Ionosphere, Academic, San Diego, Calif.

Kelley, M. C., D. T. Farley, E. Kudeki, and C. L. Siefring (1984), A model for equatorial explosive spread F, Geophys. Res. Lett., 11(12), 1168-1171.

Kelley, M. C., J. G. Ding, and R. H. Holzworth (1990), Intense ionospheric electric field and magnetic field pulses generated by lightning, Geophys. Res. Lett., 17(12), 2221-2224.

Kil, H., and L. J. Paxton (2006), Ionospheric disturbances during the magnetic storm of 15 July 2000: Role of the fountain effect and plasma bubbles for the formation of large equatorial plasma density depletions, J. Geophys. Res., 111, A12311, doi:10.1029/2006JA011742.

Kil, H., L. J. Paxton, S.-Y. Su, Y. Zhang, and H. Yeh (2006), Characteristics of the storm-induced big bubbles (SIBBs), J. Geophys. Res., 111 A10308, doi:10.1029/2006JA011743.

Kintner, P. M., J. Vago, S. Chesney, R. L. Arnoldy, K. A. Lynch, C. J. Pollock, and T. E. Moore (1992), Localized lower hybrid acceleration of ionospheric plasma, Phys. Rev. Lett., 68(16), 2448-2451, doi:10.1103/ PhysRevLett.68.2448.

Knudsen, D. J., D. D. Wallis, and H. G. James (1999), Tethered two-point measurements of solitary auroral density cavities, Geophys. Res. Lett., 26(19), 2933-2936.

Laakso, H., N. C. Maynard, R. F. Pfaff, T. L. Aggson, W. R. Coley, P. Janhunen, and F. A. Herrero (1997), Electric field diagnostics of the dynamics of equatorial density depletions, J. Atmos. Sol.-Terr. Phys., 59 , $1625-1631$

LaBelle, J., P. M. Kintner, A. W. Yau, and B. A. Whalen (1986), Large amplitude wave packets observed in the ionosphere in association with transverse ion acceleration, J. Geophys. Res., 91(A6), 7113-7118.

Lebreton, J.-P., et al. (2006), The ISL Langmuir probe experiment processing onboard DEMETER: Scientific objectives, description and first results, Planet. Space Sci., 54, 472-486.

Lee, J. J., K. W. Min, V. P. Kim, V. V. Hegai, K.-I. Oyama, F. J. Rich, and J. Kim (2002), Large density depletions in the nighttime upper ionosphere during the magnetic storm of July 15, 2000, Geophys. Res. Lett., 29(3), 1032, doi:10.1029/2001GL013991.
Lynch, K., R. Arnoldy, P. Kintner, and J. Bonnell (1996), The AMICIST auroral sounding rocket: A comparison of transverse ion acceleration mechanisms, Geophys. Res. Lett., 23(23), 3293-3296.

Lynch, K. A., R. L. Arnoldy, P. M. Kintner, P. Schuck, J. W. Bonnell, and V. Coffey (1999), Auroral ion acceleration from lower hybrid solitary structures: A summary of sounding rocket observations, J. Geophys. Res., 104(A12), 28,515-28,534.

Nemec, F., O. Santolik, M. Parrot, and J. J. Berthelier (2007), Comparison of magnetospheric line radiation and power line radiation: A systematic survey using the DEMETER spacecraft, J. Geophys. Res., 112, A04301, doi:10.1029/2006JA012134.

Ott, E. (1978), Theory of Rayleigh-Taylor bubbles in the equatorial ionosphere, J. Geophys. Res., 83(A5), 2066-2070.

Parrot, M., et al. (2006), The magnetic field experiment IMSC and its data processing onboard DEMETER: Scientific objectives, description and first results, Planet. Space Sci., 54, 441-455.

Pécseli, H., K. Iranpour, Ø. Hotter, B. Lybekk, J. Holtet, J. Trulsen, A. Eriksson, and B. Holback (1996), Lower hybrid wave cavities detected by the FREJA satellite, J. Geophys. Res., 101(A3), 5299-5316.

Pottelette, R., M. Malingre, J. J. Berthelier, and E. Seran (2007), Filamentary Alfvénic structures excited at the edges of equatorial plasma bubbles, Ann. Geophys., 25, 1-7.

Robinson, P. A. (1999), Nonlinear lower hybrid structures in auroral plasmas: Comparison of theory with observations, Adv. Space Res., 23, 1679-1688.

Robinson, P. A., A. Melatos, and W. Rozmus (1996), Lower-hybrid wave collapse, Phys. Plasmas, 3, 133-144.

Rodger, C. J., N. R. Thomson, and R. L. Dowden (1995), VLF line radiation observed by satellite, J. Geophys. Res., 100(A4), 5861-5869.

Rodger, C. J., M. A. Clilverd, K. E. Yearby, and A. J. Smith (2000), Is magnetospheric line radiation man-made?, J. Geophys. Res., 105(A1), $15,981-15,990$

Santolik, O. (2003), Propagation analysis of STAFF-SA data with coherency tests: A user's guide to PRASSACO, Technical Report LPCE/NTS 073D, LPCE/CNRS, Orléans, France.

Scherliess, L., and B. G. Fejer (1997), Storm time dependence of equatorial disturbance dynamo zonal electric fields, J. Geophys. Res., 102(A11), 24,037-24,046.

Schuck, P. W., and J. W. Bonnell (2003b), Ray trajectories of lower hybrid solitary structures, J. Geophys. Res., 108(A5), 1175, doi:10.1029/ 2002JA009716.

Schuck, P. W., C. E. Seyler, J. L. Pinçon, J. W. Bonnell, and P. M. Kintner (1998), Theory, simulation, and observation of discrete eigenmodes associated with lower hybrid solitary structures, J. Geophys. Res., 103(A4), $6935-6953$

Schuck, P. W., G. I. Ganguli, and P. Kintner (2002), The role of lowerhybrid-wave collapse in the auroral ionosphere, Phys. Rev. Lett., 89, doi:10.1103/PhysRevLett.89.065002.

Schuck, P. W., J. W. Bonnell, and P. Kintner (2003), A review of lower hybrid solitary structures, IEEE Trans. Plasma Sci., 31, 1125-1176.

Shapiro, V. D., V. I. Shevchenko, G. I. Soloviev, V. P. Kalinin, R. Bingham, R. Z. Sagdeev, M. Ashour-Abdalla, J. Dawson, and J. J. Su (1993), Wave collapse at the lower hybrid resonance, Phys. Fluids, B5, 3148-3162.

Singh, S., D. K. Bamgboye, J. P. McClure, and F. S. Johnson (1997), Morphology of equatorial plasma bubbles, J. Geophys. Res., 102(A9), 20,019-20,029.

Su, S.-Y., H. C. Yeh, C. K. Chao, and R. A. Heelis (2002), Observation of a large density dropout across the magnetic field at $600 \mathrm{~km}$ altitude during the 6-7 April 2000 magnetic storm, J. Geophys. Res., 107(A11), 1404, doi:10.1029/2001JA007552.

Temerin, M. (1978), The polarization, frequency, and wavelengths of highlatitude turbulence, J. Geophys. Res., 83(A6), 2609-2616.

Tjulin, A., A. I. Eriksson, and M. André (2003), Lower hybrid cavities in the inner magnetosphere, Geophys. Res. Lett., 30(7), 1364, doi:10.1029/ 2003GL016915.

Vago, J. L., P. M. Kintner, S. W. Chesney, R. L. Arnoldy, K. A. Lynch, T. E. Moore, and C. J. Pollock (1992), Transverse ion acceleration by localized lower hybrid waves in the topside auroral ionosphere, J. Geophys. Res., 97(A11), 16,935-16,957.

J.-J. Berthelier and M. Malingre, Centre d'étude des Environnements Terrestre et Planétaires/Centre National de la Recherche Scientifique, 4 Avenue de Neptune, F-94107 Saint-Maur-des-Fosses, France. (michel. malingre@cetp.ipsl.fr)

J. Jasperse, Air Force Research Laboratory, Hanscom Air Force Base, 29 Randolph Rd., Bedford, MA 01731, USA

M. Parrot, Laboratoire de Physique et Chimie de l'Environnement, 3A Avenue de la Recherche Scientifique, F-45071 Orléans CEDEX 2, France.

R. Pfaff, Goddard Space Flight Center/National Aeronautics and Space Administration, Code 696, Greenbelt, MD 20771, USA. 